\title{
An Eulerian CFD Model and X-ray Radiography for Coupled Nozzle Flow and Spray in Internal Combustion Engines 放
}

\author{
Q. Xue ${ }^{\mathrm{a}, *}$, M. Battistoni ${ }^{\mathrm{a}}$, C. F. Powell ${ }^{\mathrm{a}}$, D. E. Longman ${ }^{\mathrm{a}}$, S.P. Quan ${ }^{\mathrm{b}}$, E. Pomraning ${ }^{\mathrm{b}}$, P. K. Senecal ${ }^{\mathrm{b}}$, D. P. Schmidt $^{\mathrm{c}}$, \\ S. Som ${ }^{\mathrm{a}}$ \\ ${ }^{a}$ Energy Systems Division, Argonne National Laboratory, Argonne, IL, 60439, USA \\ ${ }^{b}$ Convergent Science Inc., Middleton, WI, 53562, USA \\ ${ }^{c}$ Department of Mechanical and Industrial Engineering, University of Massachusetts, Amherst, MA, 01002, USA
}

\begin{abstract}
This paper implements a coupled approach to integrate the internal nozzle flow and the ensuing fuel spray using a Volume-of-Fluid (VOF) method in the finite-volume framework. A VOF method is used to model the internal nozzle two-phase flow with a cavitation description closed by the homogeneous relaxation model of Bilicki and Kestin (1990). An Eulerian single velocity field approach by Vallet et al. (2001) is implemented for near-nozzle spray modeling. This Eulerian approach considers the liquid and gas phases as a complex mixture with a highly variable density to describe near nozzle dense sprays. The liquid mass fraction is transported with a model for the turbulent liquid diffusion flux into the gas. Fully-coupled nozzle flow and spray simulations are performed in three dimensions and validated against the x-ray radiography measurements of Kastengren et al. (2014) for a diesel fuel surrogate. A standard $k-\epsilon$ Reynolds Averaged Navier Stokes based turbulence model is used in this study and the influence of model constants is evaluated. First, the grid convergence study is performed. The effect of grid size is also evaluated by comparing the fuel distribution against experimental data. Finally, the fuel distribution predicted by the coupled Eulerian approach is compared against that by Lagrangian-Eulerian spray model along with experimental data. The coupled Eulerian approach provides a unique way of coupling the nozzle flow and sprays so that the effects of in-nozzle flow can be directly realized on the fuel spray. Both experiment and numerical simulations show noncavitation occurring for this injector with convergent nozzle geometry. The study shows that the Eulerian approach has advantages over near-field dense spray distributions.
\end{abstract}

Keywords: Computational fluid dynamics (CFD), Eulerian, Internal combustion engines (ICEs), Nozzle flow, Sprays, X-ray radiography

\section{Introduction}

With the challenge of engine fuel-efficiency and emission standards, high injection pressure and direct injection techniques are extensively developed and implemented to achieve better air-fuel mixture formation for controlling combustion and pollutant formation processes. This has necessitated further understanding of the complex in-nozzle flow and near-nozzle spray phenomena both experimentally and numerically (U.S. DOE, 2011; Powell et al., 2011;

\footnotetext{
The submitted manuscript has been created by UChicago Argonne, LLC, Operator of Argonne National Laboratory ("Argonne"). Argonne, a U.S. Department of Energy Office of Science laboratory, is operated under Contract No. DE-AC02-06CH11357. The U.S. Government retains for itself, and others acting on its behalf, a paid-up nonexclusive, irrevocable worldwide license in said article to reproduce, prepare derivative works, distribute copies to the public, and perform publicly and display publicly, by or on behalf of the Government.

${ }^{*}$ Corresponding author.

Email address: queeeanl.gov (Q. Xue)
}

Preprint submitted to IJMF

November 28, 2014

(C) 2014. This manuscript version is made available under the Elsevier user license http://www.elsevier.com/open-access/userlicense/1.0/ 
Pickett et al., 2014). For example, researchers across the world have made various contributions in these areas in the Engine Combustion Network (ECN) (ECN, 2010) in the past few years.

The discrete droplet method (DDM) of Dukowicz (1980) has been widely used in the Lagrangian-Eulerian approach for modeling fuel sprays in Internal Combustion Engines (ICEs). The Lagrangian-Eulerian approach describes the gas-phase in an Eulerian manner while the liquid phase is modeled in a Lagrangian fashion with sub-models for various physical processes (such as breakup, collision, etc.). This approach together with some amount of model calibration has been a great success for modeling the spray, mixture formation, combustion, and engine-out emissions (Amsden et al., 1989; Reitz and Rutland, 1995; Senecal et al., 2003; Torres and Trujillo, 2006; Kong et al., 2007; Lucchini et al., 2009; Som and Aggarwal, 2010) over several decades. The known challenges for this model are the mesh dependency and near-nozzle dense spray assumptions. The mesh dependency is attributed to the mass, momentum, and energy coupling between the discrete droplets and carrier gas phase, and the spray sub-models. The Adaptive Mesh Refinement (AMR) method has been implemented to numerically better resolve the gas-droplet interphase transfer using locally high mesh resolution (Chang and Haworth, 1997; Senecal et al., 2007; Xue et al., 2008; Xue and Kong, 2009) with less computational penalty. Grid convergence studies for fuel spray were conducted by Senecal et al. (2013a) with a Reynolds Averaged Navier Stokes (RANS) turbulence model and by Senecal et al. (2013b); Xue et al. (2013b); Senecal et al. (2014) with different sub-grid scale models in large eddy simulations (LES) on finest mesh resolutions of $0.03125 \mathrm{~mm}$ by using AMR and fixed embedding techniques. Schmidt and Senecal (2002) and Hou and Schmidt (2006) developed a new collision algorithm with a secondary collision mesh. Schmidt and Rutland (2004) and Are et al. (2005) developed a collision sub model, a collision mesh approach, and secondorder gas-to-liquid coupling to better predict the dense spray on a typical mesh size using the RANS approach within the Lagrangian-Eulerian framework. By using fine meshes for gas-droplet two-way coupling and large number of parcels for Lagrangian particle description, Senecal et al. (2014, 2013b); Xue et al. (2013b) showed that grid convergency was achieved with $0.125 \mathrm{~mm}$ resolution with RANS and $0.0625 \mathrm{~mm}$ resolution with LES in terms of spray liquid and vapor penetrations. Note that a $0.5 \mathrm{~mm}$ mesh resolution or coarser is widely used for Lagrangian-Eulerian spray and engine simulations. Schmidt (2006) showed that a diminishing grid size and very high number of parcels are required to resolve gas-droplet interaction and reduce the statistical error due to Largrangian parcels to achieve grid convergence. The other issue is the dense spray near nozzle region which may not be accurately described with discrete droplet by the Lagrangian approach due to dominant mixing (Siebers, 1998, 1999). Different models of injection are proposed to mimic the physics of the primary atomization in this dense region near the fuel injector exit. For example, the "blob" model of Reitz (1987) is widely used.

The Eulerian-Eulerian approach for spray modeling has made significant progress in the past decade. Bekdemir et al. (2013) predicted diesel combustion characteristics using a mesoscopic Eulerian formalism for the dispersed liquid phase in the in-house AVBP solver. An injector model was implemented (Martinez et al., 2010) to deal with the dense spray region close to the injector. This model uses algebraic relations to bridge the dense region by imposing physical flow conditions at a distance approximately 10 nozzle diameters downstream of the injector outflow plane. 
An Eulerian model was originally proposed by Vallet et al. (2001) for the atomization of a liquid jet which considered atomization as a turbulent mixing process. Recently, variations of this model have been implemented by several groups to study its capability for near nozzle and far-field sprays (Lebas et al., 2005; Demoulin et al., 2007; Lebas et al., 2009; Ning et al., 2009; Trask et al., 2012; Chesnel et al., 2012; Duret et al., 2013; Garcia-Oliver et al., 2013; Salvador et al., 2014). The global parameters such as liquid penetration, Sauter Mean Diameter (SMD), and axial velocity are compared with measurements for validation of the models. Wang et al. (2014) implemented a two-fluid model in Eulerian framework for coupled simulations of internal and external nozzle flows. The implementation was tested on 2-D cavitating liquid jet.

Another critical component for accurate spray modeling is that the boundary conditions for the spray should be linked with in-nozzle flow simulations. Schmidt et al. $(1999,2010)$ developed a mixture-based model to calculate the cavitating nozzle flow considering thermodynamic equilibrium and non-equilibrium conditions. Zhao et al. (2014) implemented and validated the above mixture-based model in a VOF method for in-nozzle flow simulations. Battistoni et al. (2014) compared different modeling approaches for in-nozzle flows against x-ray measurements of cavitating flows. Habchi et al. (2008) performed LES modeling of the complex phenomena of nucleation, growth, and coalescence of bubbles at sub-grid scale level using a thermodynamic equilibrium approach. It is well known from literature that the turbulence, cavitation, nozzle geometry, and the motion of injector needle can directly impact the spray development (Bergwerk, 1959; Arcoumains and Gavaises, 1998; Soteriou et al., 2001, 2006; Powell et al., 2011). The incorporation of these findings into modeling the spray inlet conditions can facilitate spray models to be more predictive for real conditions. von Berg et al. (2002) have proposed to map the results of an Eulerian nozzle flow calculation onto an auxiliary grid in the orifice cross section for initializing a Lagrangian spray simulation. Validations and applications of such approach have been reported on up-scaled nozzles (von Berg et al., 2005) and on real size diesel nozzles (Battistoni and Grimaldi, 2012). Wang et al. (2011) studied the atomization process of diesel spray coupled with the nozzle flow through a real-time interpolation procedure. Som et al. (2009) have developed the Kelvin Helmholtz Aerodynamic Cavitation Turbulence (KH-ACT) primary breakup model to include the effects of cavitation, turbulence, and in-nozzle geometry by statically coupling the nozzle flow simulations with the Lagrangian spray. Since the nozzle flow features are incorporated in the model, the predicted spray dispersion, spray axial velocity, and spray cone angle showed improvement when compared with x-ray data. The effects of nozzle flow and geometry on the combustion and emission characteristics were also shown under diesel engine conditions (Som and Aggarwal, 2010; Som et al., 2011).

Several optical techniques have been used to characterize spray parameters under both combusting and noncombusting conditions. The data-set from these studies include spray penetration, cone angle, liquid length, flame lift-off length, and the velocity field near nozzle region (Naber and Siebers, 1996; Siebers, 1998; Pickett and Siebers, 2004). While these diagnostics have provided important insights regarding the far-field spray behavior, they can provide limited data regarding the near-nozzle fuel distribution. Some success has been achieved by the advanced optical diagnostics to overcome the optical density limitations in the dense spray regime (Payri et al., 2005; Linne et al., 


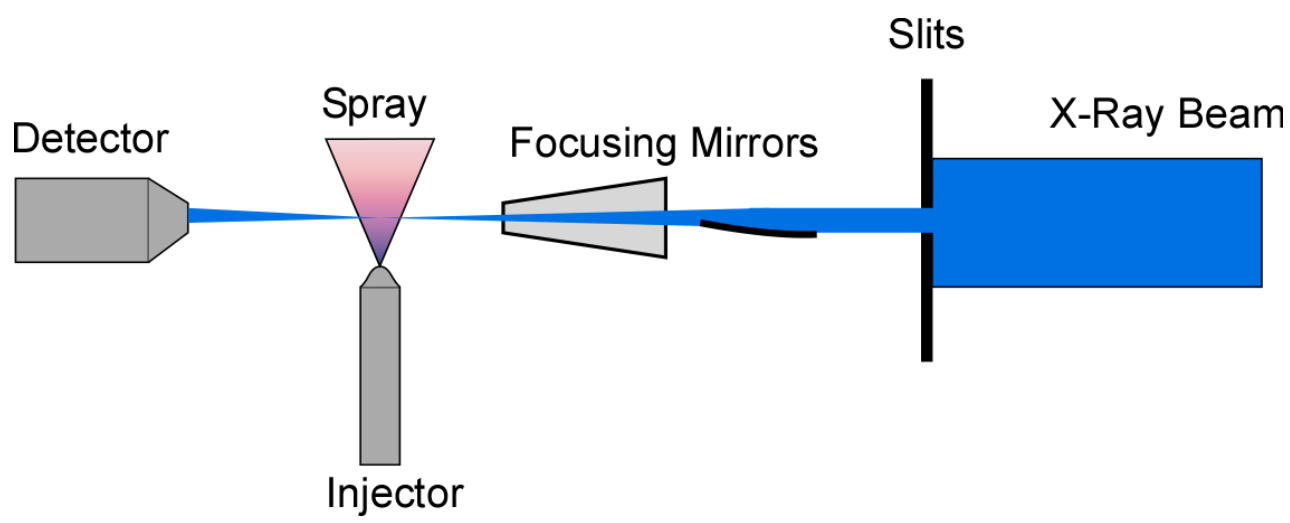

Figure 1: Schematic of spray radiography setup at the 7BM beamline.

2006). x-ray radiography has been developed as a spray diagnostic tool that specializes in measuring the density in the spray formation region (Powell et al., 2004; Kastengren et al., 2009a,b). Since the main interaction between $\mathrm{x}$-rays and fuel spray is absorption, this technique allows for quantitative measurements of fuel density in the dense spray region. X-ray radiography has been used to characterize the near-nozzle distribution of fuel sprays under a wide variety of ambient and injection conditions. Pickett et al. (2014) compared the near-field dense spray structure (spray boundary) between the light-based optical microscopy and x-ray radiography.

It is clear from our literature review that Eulerian-Eulerian models existing in the literature have not been extensively tested on their ability to capture near nozzle fuel distribution under diesel spray conditions. The major objective of this study is to implement a turbulent-mixing based Eulerian model to resolve the near nozzle dense spray region by linking the nozzle flow simulations with downstream spray development. This work is motivated by the need for predictive near nozzle spray models. The coupled nozzle flow and Eulerian spray simulations are extensively validated against $\mathrm{x}$-ray radiography data. Following model validation, parametric studies are conducted to assess the influence of different turbulence model constants, Schmidt number effects, and mesh resolution on near nozzle fuel distribution. Also, the coupled Eulerian spray model is compared against state-of-the-art Lagrangian-Eulerian spray simulations.

The rest of this paper is arranged as follows: first, the experimental method is briefly introduced in Sec. 2. The model implementation and numerical algorithms in the CFD code are given in Sec. 3. The computational domain and simulation set-up is briefly described followed by the description of ECN experimental conditions for Spray A under non-evaporating conditions in Sec. 4. Experimental validation of the coupled Eulerian approach is presented followed by parametric studies on the influence of model constants on near nozzle fuel distribution in Sec. 5. Finally, the conclusions are drawn in Sec. 6.

\section{Experimental methods}

While mechanical and optical diagnostics have been used extensively to study diesel sprays, such techniques typically cannot penetrate the optically dense spray formation region near the nozzle of a diesel spray (Sick and 


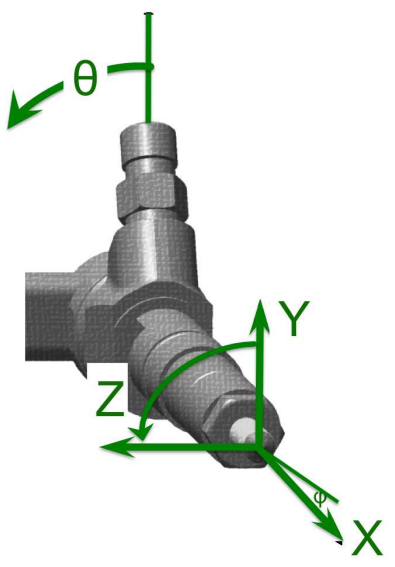

Figure 2: Illustration of measured Spray A injector and coordinate system (ECN, 2010).

Stojkovic, 2001). Recently, advanced optical diagnostics have been developed to improve upon conventional optical diagnostics in strongly scattering flowfields (Leick et al., 2011; Linne et al., 2006). X-ray radiography has been developed to generate quantitative measurements of the near-nozzle fuel distribution at high spatial and temporal resolution. Such measurements of the fuel density during the primary breakup are used in this work for validating the internal flow simulations.

The measurements were performed at the 7BM beamline at the Advanced Photon Source at Argonne National Laboratory. An experimental schematic is shown in Fig. 1. A focused X-ray beam (5 microns in size FWHM) at $8 \mathrm{keV}$ photon energy passed through a spray chamber with X-ray transparent windows. The spray was emitted into a quiescent ambient environment of nitrogen gas at room temperature and elevated pressure.The transmitted X-ray intensity, as a function of time, was recorded with a photodiode and digitizing oscilloscope. The Beer-Lambert law allowed the transmission to be converted to mass of fuel using a single absorption coefficient.

Measurements were performed point-by-point; each two-dimensional projection of the spray is the compilation of several hundred individual measurement coordinates. At each measurement location, 32-128 individual spray events were averaged to improve the data quality. Hence, the reported data reflect only persistent, ensemble-averaged features of the spray. X-ray radiography measurements provide a quantitative two dimensional visualization of the average fuel distribution. Each measurement point represents an integration of the fuel density along the beam path. As such, the final data represent the ensemble averaged three-dimensional fuel density projected onto a plane. The fuel distribution data are thus reported as a projected density (mass/area). Further details regarding the beamline setup and data processing procedures are given elsewhere (Kastengren and Powell, 2007).

The measurements performed on a Spray A injector from the ECN (Pickett et al., 2010) are described here for the CFD model validation. The detailed conditions for the x-ray radiography measurements are listed in Tab. 1. It should be noted that the ambient gas for these experiments was $\mathrm{N}_{2}$ at room temperature, different from the standard 
Table 1: Specifications for non-evaporating Spray A of ECN for X-ray radiography measurement (ECN, 2010).

\begin{tabular}{ll}
\hline Ambient gas temperature & $303(\mathrm{~K})$ \\
Ambient gas pressure & $2.0(\mathrm{MPa})$ \\
Ambient gas density & $22.8\left(\mathrm{~kg} / \mathrm{m}^{3}\right)$ \\
Ambient gas $_{2}($ by volume $)$ & $100 \%$ \\
Nozzle K factor $^{a}\left(\left(\mathrm{~d}_{\text {inlet }^{-}} \mathrm{d}_{\text {outlet }}\right) / 10[\mathrm{use} \mu \mathrm{m}]\right)$ & 1.5 \\
Fuel injector nozzle outlet diameter $($ nominal) & $0.090(\mathrm{~mm})$ \\
Number of holes & single hole \\
Fuel injection pressure $($ nominal $)$ & $150(\mathrm{MPa})$ \\
Fuel & $\mathrm{n}$-dodecane \\
Fuel temperature at nozzle & $343(\mathrm{~K})$ \\
Injection duration & $1.5(\mathrm{~ms})$ \\
Injected mass & $3.5(\mathrm{mg})$ \\
\hline
\end{tabular}

${ }^{a}$ The corresponding convergence angle is about 1.0 degree; atan(convergence angle) $=$ nozzle length $/\left(\mathrm{d}_{\text {inlet }}-\mathrm{d}_{\text {outlet }}\right)$

ECN Spray A condition of high-temperature. This is due to the x-ray transparent polymer windows used in these experiments, which cannot be used at high temperature. The current experiments have, however, matched the ambient density of the Spray A specification at the expense of not matching the ambient pressure. Density is expected to be a more critical parameter for spray breakup than pressure (Naber and Siebers, 1996). The other difference is the injector tip temperature for these experiments was approximately $65^{\circ} \mathrm{C}$, rather than the $90^{\circ} \mathrm{C}$ specification. The radiography measurement conditions, rather than the Spray A specifications, were used for validation of the Eulerian spray model presented in this work. The x-ray radiography spray measurements will be discussed side-by-side with numerical results in Sec. 5.

Some unique insights from the x-ray radiography spray measurements are highlighted here (Kastengren et al., 2014). Fig. 3 shows the distribution of projected density across the spray during quasi-steady state at four different viewing angles measured $0.1 \mathrm{~mm}$ downstream of the nozzle exit. The spray appears to have different structures depending on the view examined. The difference between these distributions are due to the asymmetry in the spray plume.

\section{Computational formulations}

This section briefly introduces the Eulerian and Lagrangian-Eulerian models implemented and used in this work. 


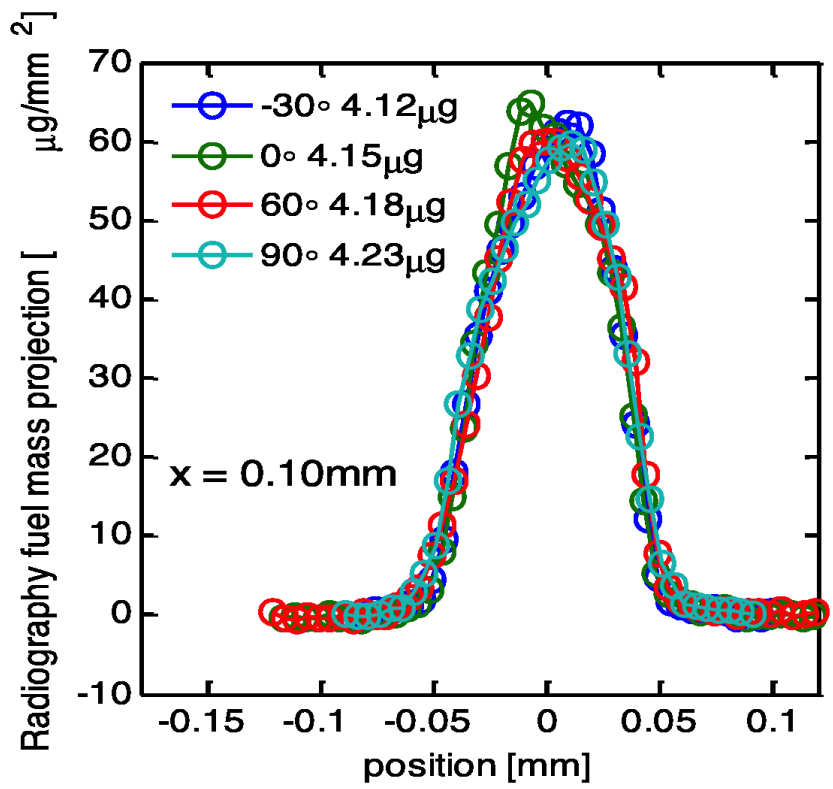

Figure 3: Projected density across the spray axis at $0.1 \mathrm{~mm}$ nozzle exit downstream with the four viewing angles $(\theta)$

\subsection{Eulerian model}

In an Eulerian model (Vallet et al., 2001), the gas and liquid fuel are described as a single fluid mixture. It is assumed that the large-scale flow features dominate rather than the smaller scale structures under the high Reynolds number and Weber number condition encountered in the near nozzle dense spray region. The governing equations are summarized here.

The fuel mass fraction $(\tilde{Y})$ transport equation is given by:

$$
\frac{\partial \bar{\rho} \tilde{Y}}{\partial t}+\frac{\partial \bar{\rho} \tilde{u}_{i} \tilde{Y}}{\partial x_{i}}=-\frac{\partial \bar{\rho} \widetilde{u_{i}^{\prime} Y^{\prime}}}{\partial x_{i}}-\bar{\rho} \tilde{\dot{Y}}_{\text {evap }}
$$

where $u^{\prime}$ and $Y^{\prime}$ are the turbulent fluctuation in velocity and liquid fuel mass fraction. The last term of the righthand-side is the source term due to evaporation which is zero in this case since the simulations are performed under non-evaporating conditions. Under the assumption of an immiscible two-phase mixture, the mass-averaged density of the mixture is given by:

$$
\frac{1}{\bar{\rho}}=\frac{\tilde{Y}}{\rho_{l}}+\frac{1-\tilde{Y}}{\bar{\rho}_{g}}
$$

Here, the gas density is governed by an equation of state $\left(\bar{\rho}_{g}=\bar{p} /\left(R_{g} \tilde{T}\right)\right)$ and liquid phase has a constant density. Here $p$ is the cell pressure, $R_{g}$ is the gas constant calculated by $R_{g}=R / W_{g}$ with universal gas constant $(R)$, gas molecular weight $W_{g}$, and $T$ is the cell temperature.

The closure for the liquid mass transport in Eqn. (1) is based on a standard turbulent gradient flux model:

$$
\widetilde{\rho} \widetilde{u_{i}^{\prime} Y^{\prime}}=\frac{\mu_{t}}{S c_{t}} \frac{\partial \tilde{Y}}{\partial x_{i}}
$$


where $S c_{t}$ is the turbulent Schmidt number which is an input to the model.

The momentum equation is given:

$$
\frac{\partial \bar{\rho} \tilde{u}_{i}}{\partial t}+\frac{\partial \bar{\rho} \tilde{u}_{i} \tilde{u}_{j}}{\partial x_{j}}=-\frac{\partial \bar{p}}{\partial x_{i}}+\frac{\partial \sigma_{i j}}{\partial x_{j}}+\frac{\partial \tau_{i j}}{\partial x_{j}}
$$

where $\sigma_{i j}$ and $\tau_{i j}$ are the viscous and modeled Reynolds stress tensor, respectively. $\tau_{i j}$ is calculated using the classical Boussinesq eddy viscosity concept:

$$
\tau_{i j}=\mu_{t}\left(\frac{\partial \tilde{u}_{i}}{\partial x_{j}}+\frac{\partial \tilde{u}_{j}}{\partial x_{i}}-\frac{2}{3} \frac{\partial \tilde{u}_{k}}{\partial x_{k}} \delta_{i j}\right)-\frac{2}{3} \bar{\rho} k \delta_{i j}
$$

and $\delta_{i j}$ is the Kronecker delta. The standard $k-\epsilon$ model is used to close Eqn. (5) through:

$$
\mu_{t}=\bar{\rho} C_{\mu} \frac{k}{\epsilon}
$$

Turbulent kinetic energy $(k)$ is given:

$$
\frac{\partial \bar{\rho} k}{\partial t}+\frac{\partial \bar{\rho} \tilde{u}_{i} k}{\partial x_{i}}=\tau_{i j} \frac{\partial \tilde{u}_{i}}{\partial x_{j}}+\frac{\partial}{\partial x_{j}}\left(\frac{\mu}{P r_{t k e}} \frac{\partial k}{\partial x_{j}}\right)-\bar{\rho} \epsilon
$$

where the turbulent dissipation $(\epsilon)$ is transported by,

$$
\frac{\bar{\rho} \epsilon}{\partial t}+\frac{\partial \bar{\rho} \tilde{u}_{i} \epsilon}{\partial x_{i}}=\frac{\partial}{\partial x_{j}}\left(\frac{\mu_{t}}{P r_{\epsilon}} \frac{\partial \epsilon}{\partial x_{j}}\right)-C_{\epsilon 3} \bar{\rho} \epsilon \frac{\partial \tilde{u}_{i}}{\partial x_{i}}+\left(C_{\epsilon 1} \frac{\partial \tilde{u}_{i}}{\partial x_{j}} \tau_{i j}-C_{\epsilon 2} \bar{\rho} \epsilon\right) \frac{\epsilon}{k}-\bar{\rho} R
$$

where $R$ is dependent on the turbulence model, $C_{\epsilon 1}, C_{\epsilon 2}$, and $C_{\epsilon 3}$ are model constants with values of $1.44,1.92$, and -1.0 , respectively for the standard $k-\epsilon$ model.

The energy equation $(\tilde{e})$ is given by:

$$
\frac{\partial \bar{\rho} \tilde{e}}{\partial t}+\frac{\partial \bar{\rho} \tilde{e} \tilde{u}_{i}}{\partial x_{i}}=-\bar{p} \frac{\partial \tilde{u}_{i}}{\partial x_{i}}+\left(\sigma_{i j}+\tau_{i j}\right) \frac{\partial \tilde{u}_{i}}{\partial x_{i}}+\frac{\partial}{\partial x_{i}}\left(K \frac{\partial \tilde{T}}{\partial x_{i}}\right)+\frac{\partial}{\partial x_{i}}\left(\bar{\rho} D_{t} \sum_{m} \tilde{h}_{m} \frac{\partial \tilde{Y}_{m}}{\partial x_{i}}\right)
$$

where $K, \tilde{T}, D_{t}$, and $\tilde{h}_{m}$ are conductivity, turbulent diffusion, gas temperature, and enthalpy of species $m$, respectively.

A VOF method is used to model the two-phase flow (Zhao et al., 2014; Quan et al., 2014) in CONVERGE (Senecal et al., 2007). In the VOF method, a volume fraction $\alpha$ is used to represent the volume fraction of liquid and gas, and is defined as follows:

$$
\alpha= \begin{cases}0 & \text { if the computational cell is filled with pure liquid } \\ 1 & \text { if the computational cell is filled with pure gas } \\ (0,1) & \text { if the computational cell is filled with both liquid and gas }\end{cases}
$$

Typically, the volume fraction can be solved with a conservation equation. In the present work, the volume fraction is not solved directly from a transport equation. Instead, it is calculated with the transported mass fraction by:

$$
\alpha=\frac{(1-\tilde{Y}) / \bar{\rho}_{g}}{(1-\tilde{Y}) / \bar{\rho}_{g}+\tilde{Y} / \rho_{l}}
$$

where $\tilde{Y}$ is the mass fraction and subscripts $g$ and $l$ denote gas and liquid, respectively. 


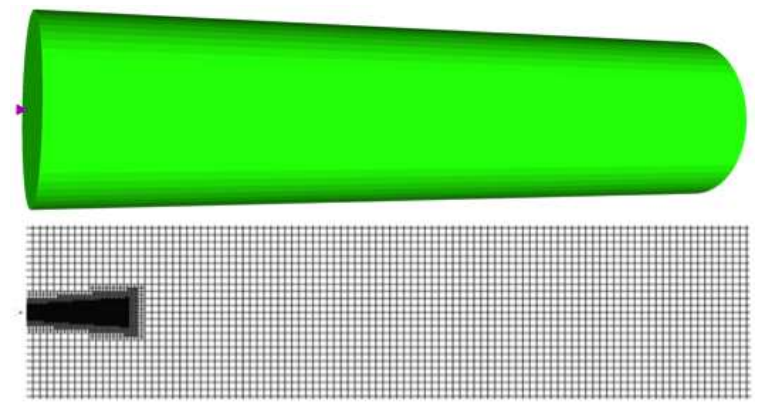

Figure 4: The three-dimensional computational domain (top) and mesh (bottom) for Spray A simulations.

\subsection{Lagrangian-Eulerian simulation setup}

The LE simulations were performed with the injection modeled using the "blob" injection approach (Reitz and Diwakar, 1987). The Kelvin Helmholtz (KH) (Reitz, 1987) and the Rayleigh Taylor (RT) (Patterson and Reitz, 1998) models were used for droplet secondary breakup process. The "no time counter" algorithm (Schmidt and Rutland, 2000) was adopted to account for droplet collisions. A dynamic drag model (Liu and Reitz, 1993) and a turbulent dispersion model were used to model droplet drag and dispersion. The gas-phase is solved using an Eulerian approach with both the phases exchanging mass, momentum, and energy. The authors have extensively studied the influence of grid-size and number of parcels in their previous studies (Senecal et al., 2013a,b; Xue et al., 2013b; Senecal et al., 2014) and concluded that for this injector, injection and ambient conditions the LE simulations grid converge at 125 microns. Since 125 microns is larger than the nozzle diameter, LE results are presented in this paper at a finer resolution, i.e., at 62.5 microns. The authors have also investigated the influence of number of Lagrangian parcels injected (Senecal et al., 2013a) and concluded that 300K parcels provide statistically converged results.

\section{Computational domain and conditions of Spray A}

The single-hole Spray A injector and conditions from the ECN were used to validate the Eulerian model applied to coupled nozzle flow and spray. The x-ray radiography data for validation is obtained under non-evaporating conditions with n-dodecane as the fuel. Since these experiments are performed in cold spray conditions the ambient pressure is changed to ensure the same ambient density as the Spray A baseline condition. Further details about the experimental set-up are provided in Table 1. It should be noted that the x-ray data is ensemble-averaged over multiple shots. These ensemble-averaged data are compared against RANS based calculations.

Three-dimensional simulations were performed by coupling the nozzle calculation with the downstream spray. The 3-D computational domain and a 2-D cut-plane view of the mesh for the simulations are shown in Figure 4 along with the Spray A injector (the red small region on the top-left image). A close view of the fuel injector is also shown in Figure 5. It can be clearly seen from this image that the nozzle orifice is offset and is not centrally located on the $\mathrm{sac}$, this matches the measured nozzle geometry. The cylindrical spray chamber has a dimension of $50 \mathrm{~mm} \times 200 \mathrm{~mm}$ 


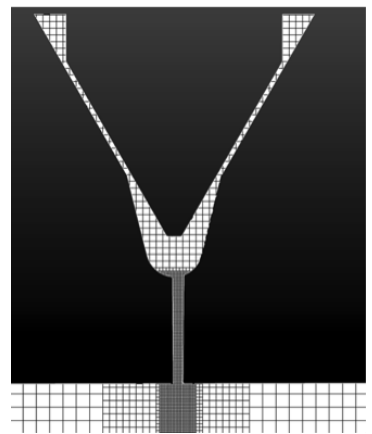

(a) Enlarged view of the nozzle

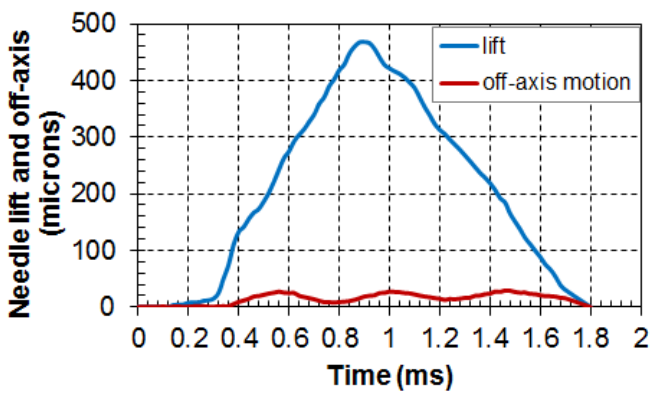

(b) Needle profiles

Figure 5: An enlarged view of the nozzle along a cut-plane showing the mesh generated in the seat, sac, orifice, and nozzle exit regions. The needle-lift and off-axis motion profiles for the Spray A simulations are also shown.

in diameter and length which is similar to the one used in experiments. Fixed embedding (as shown in Figure 4) was used in the near nozzle region with baseline grid size of $2 \mathrm{~mm}$. For the grid convergence study, five different minimum grid sizes i.e., $7.5 \mu \mathrm{m}, 10 \mu \mathrm{m}, 15 \mu \mathrm{m}, 30 \mu \mathrm{m}$, and $60 \mu \mathrm{m}$, are simulated. These fine resolutions are embedded inside the nozzle orifice and for a few diameters downstream inside the spray chamber. The corresponding nozzle diameter to cell size ratios are: $12,6,3$, and 1.5 respectively. The transient inlet boundary condition was specified by imposing a needle movement profile measured in experiments (Kastengren et al., 2014). The needle transients include both needle-lift and needle off-axis ("wobble") motions, as shown in Figure 5.

Associated with the transient needle movement profiles, pressure and temperature are specified at the inlet boundary. The turbulent intensity was set to $1 \%$ at the inlet. A "no-slip" wall boundary condition is employed at all other surfaces. This type of Eulerian model considers jet atomization as a turbulent mixing process (Vallet et al., 2001). The current model for this turbulent mixing is based on the standard turbulent gradient flux model (see Eqn. 3). It can be seen that the turbulence model constants and Schmidt number are the main parameters in this model which may require calibration. The standard k-epsilon turbulence model is used for all simulations. Pope (1978) suggested a modification to the standard k-epsilon model for accurate calculations of round jets. In this study, two $C_{\epsilon 1}$ values i.e., the standard value of 1.44 and suggested value of 1.60 for round-jets based on Pope (1978), are used. Two values of the Schmidt number $\left(S c_{t}\right)$ i.e., 0.71 and 0.90 are used to study its effect. In this paper, the baseline case uses 1.60 for $C_{\epsilon 1}$ and 0.71 for $S c_{t}$.

\section{Results and analysis}

Since the coupled Eulerian model is developed to accurately capture the near nozzle spray physics, the emphasis of this paper is to comprehensively validate this model against the near nozzle x-ray data (Kastengren et al., 2014). Firstly, in Figure 6, a snapshot of volume fraction of liquid fuel is shown at $0.51 \mathrm{~ms}$ after start of injection (ASOI). 


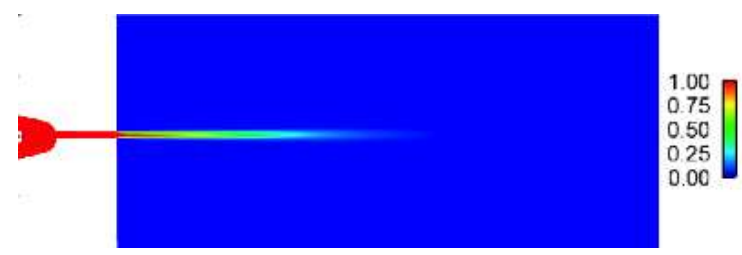

Figure 6: Contour of liquid volume fraction at a cut-plane through the center of the jet at $0.51 \mathrm{~ms}$ ASOI.

It can be seen that the injector and orifice is completely filled with of liquid fuel, i.e., there is no cavitation under the simulated conditions. The liquid jet starts to penetrate and disperse at the nozzle exit. A liquid core is also shown at the near field region.

\subsection{Numerical grid convergence}

The numerical grid convergence for the model to predict the spray was studied using the projected mass density qualitatively and quantitatively. Figures 7 and 8 plot the projected mass density contours and transverse distributions at four different locations along spray axis with four mesh resolutions at $100 \mu \mathrm{s}$ ASOI, respectively. It can be seen that finer mesh resolutions resolve the near nozzle better qualitatively from the 2-D contour plots. The projected mass density distributions are similar in $10 \mu \mathrm{m}$ and $7.5 \mu \mathrm{m}$ meshes in Figure 7 . This is also evident from the quantitative transverse distribution at different spray downstream locations in Figure 8. The transverse distributions are similar for $15 \mu \mathrm{m}, 10 \mu \mathrm{m}$, and $7.5 \mu \mathrm{m}$ meshes. Grid convergence is observed with $10-15 \mu \mathrm{m}$ resolution in terms of projected mass density. It is also worth noting that the $30 \mu \mathrm{m}$ mesh can resolve the projected mass density fairly well. $15 \mu \mathrm{m}$ smallest grid resolution simulations are used in the following studies keeping in mind computational accuracy and times.

\subsection{Validation of mass flow rate at the nozzle exit}

In order to ascertain the efficacy of the nozzle flow simulations the mass flow rate calculated from the simulation at the nozzle exit is plotted for the $15 \mu \mathrm{m}$ minimum grid size in Figure 9. For comparison purposes different rate of injection (ROI) profiles measured by Sandia National Laboratory and computed by CMT (2013) are plotted. The recommended ROI for simulations from the ECN website is also plotted in Figure 9, which is a compendium of several experimental datasets accounting for their uncertainties. The ROI profiles (from Sandia and CMT) are usually used for specifying the inlet boundary conditions from the nozzle for downstream spray simulations in Lagrangian spray calculations. This study uses the pressure inlet boundary conditions at the inlet of the injector, hence the mass flow rate at the nozzle exit is predicted by the simulations. It can be observed that the simulated mass flow rate at the nozzle exit is similar to the measurements, especially for the steady state values. There are differences between simulations and experiments during the needle transient regions which can be attributed to uncertainties in injection delay measurements. Another source of uncertainty in simulations is the need for a minimum needle lift to start the 


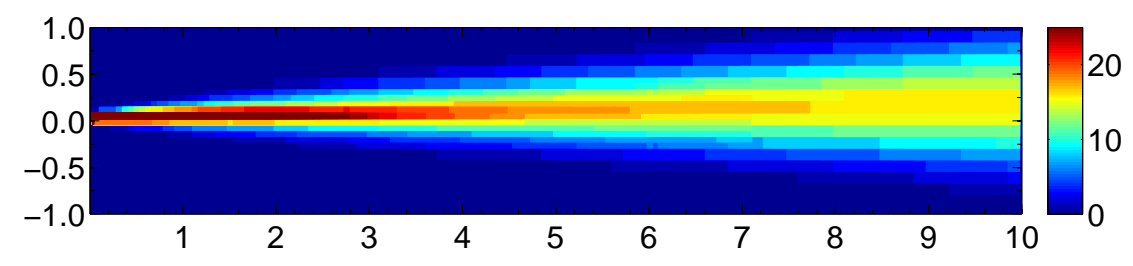

(a) $60 \mu \mathrm{m}$ grid

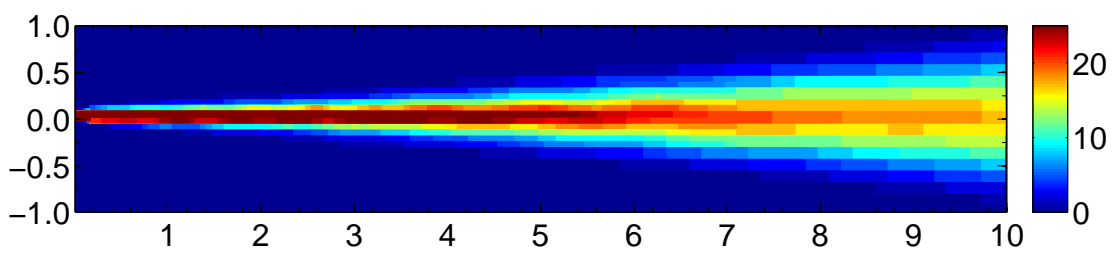

(b) $30 \mu \mathrm{m}$ grid

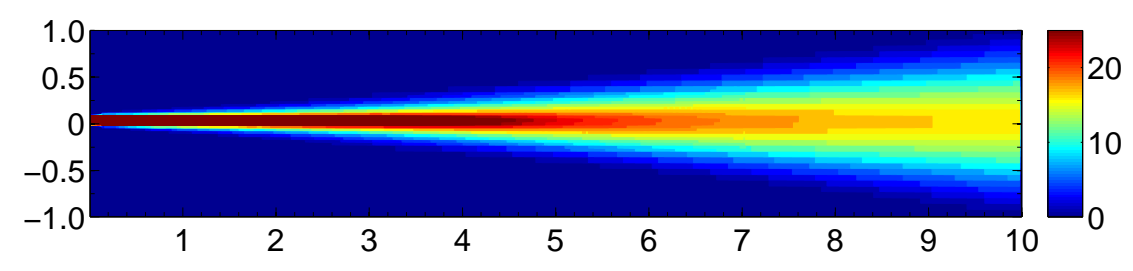

(c) $15 \mu \mathrm{m}$ grid

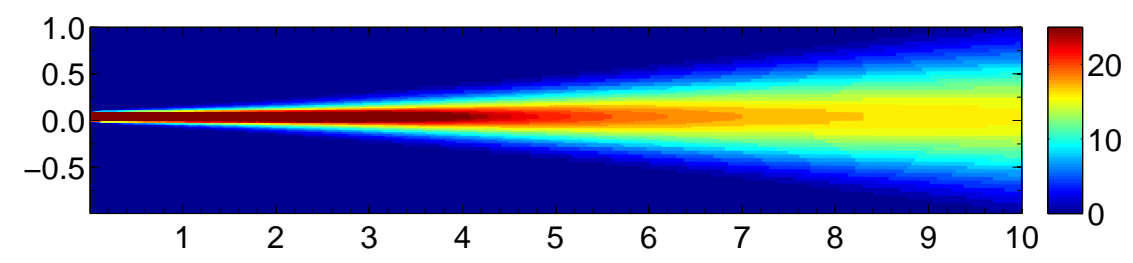

(d) $10 \mu \mathrm{m}$ grid

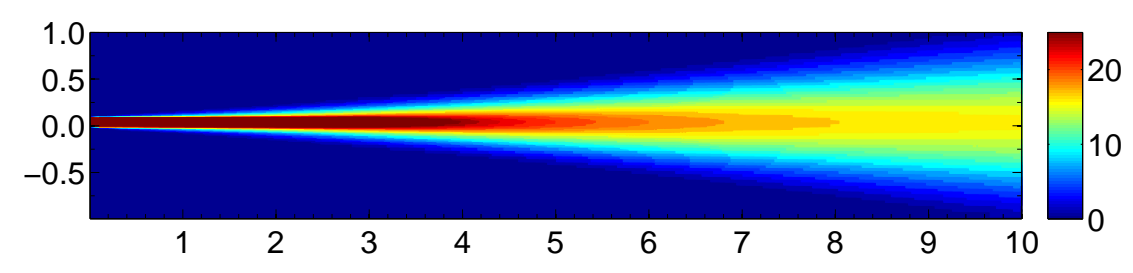

(e) $7.5 \mu \mathrm{m}$ grid

Figure 7: Projected mass density distributions $\left(\mu \mathrm{g} / \mathrm{mm}^{2}\right)$ at $100 \mu \mathrm{s}$ ASOI from the simulations with different smallest grid sizes. 


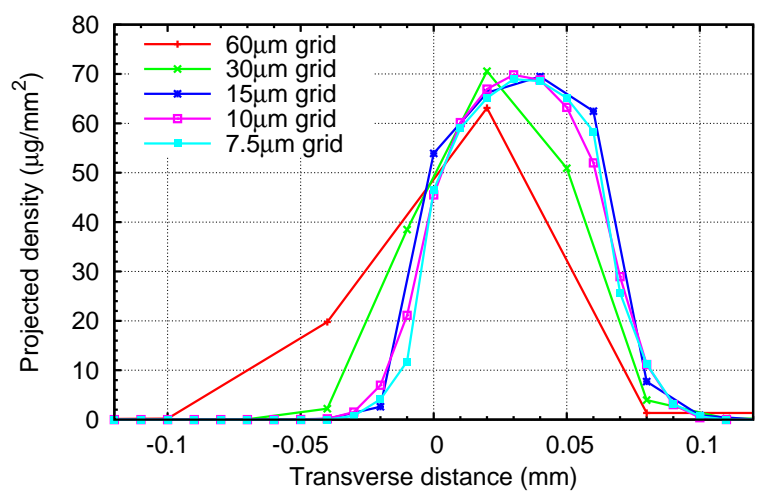

(a) $0.1 \mathrm{~mm}$

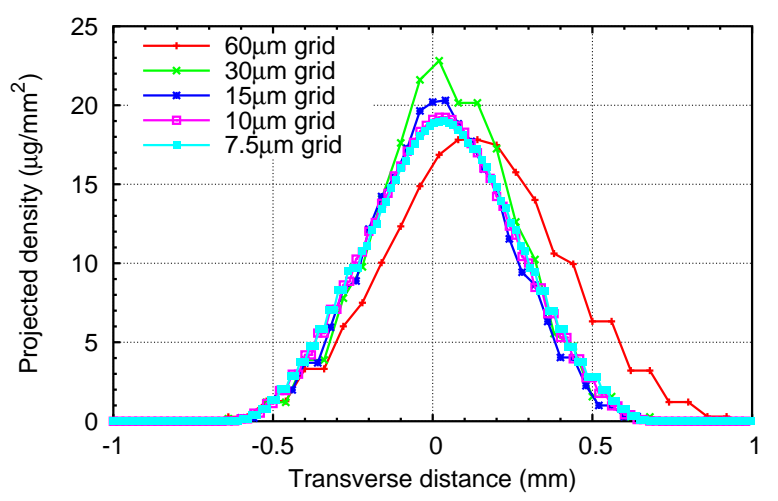

(b) $6.0 \mathrm{~mm}$

Figure 8: Transverse mass density distributions $\left(\mu \mathrm{g} / \mathrm{mm}^{2}\right)$ at $0.1 \mathrm{~mm}$ and $6.0 \mathrm{~mm}$ downstream locations at $100 \mu$ s ASOI from the simulations with different smallest grid sizes.

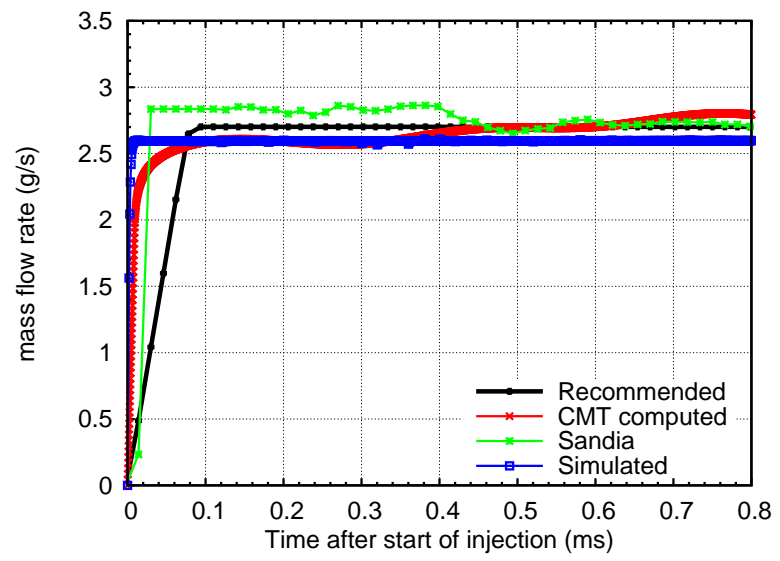

Figure 9: Mass flow rates at the nozzle exit from simulation compared against Sandia measurement, CMT online calculator, and recommended ROI for simulations from (ECN, 2010). 
simulation. This minimum lift results in a mass flow rate which may not be negligible, especially during the initial transients.

\subsection{Validation with $x$-ray data}

Following the validation of the nozzle flow simulations, the coupled Eulerian model results are compared against fuel distribution contours measured by x-ray radiography. First, the fuel distributions are compared by plotting the projected mass density from experiments and simulations at $510 \mu \mathrm{s}$ ASOI in Figure 10. In experiments the projected mass density of the fuel is calculated by a line-of-sight integration along the x-ray beam. A similar procedure is replicated in simulations to enable fair comparisons between experiments and simulations. The simulation results compare the influence of grid resolution on the near nozzle fuel distribution for the baseline set-up mentioned above i.e., $C_{\epsilon 1}$ of 1.60 and $S c_{t}$ of 0.71 . Notice that the x-ray data has a window of $1 \mathrm{~mm} \times 10 \mathrm{~mm}$ in transverse and axial directions respectively while simulation plots are provided in a $2 \mathrm{~mm} \times 10 \mathrm{~mm}$ window. From the projected density contours it is seen that the simulations can capture the fuel distribution in the very near nozzle region (i.e., within $6 \mathrm{~mm}$ ) with all the meshes. The simulations tend to over predict fuel dispersion radially beyond $2 \mathrm{~mm}$ (i.e., downstream of $2 \mathrm{~mm}$ ). The near nozzle fuel dispersion is probably best captured with the finest mesh, i.e. $10 \mu \mathrm{m}$, which is not surprising. The over prediction of radial fuel dispersion is discussed later in this paper.

Based on the above contour plots the projected density along the core of the spray axis are plotted for the four mesh sizes together with the experimental x-ray data (Kastengren et al., 2014). The projected density at the core decreases with axial distance in the near nozzle region as is expected. This trend is well captured by all the mesh resolutions (as shown in Figure 11). The values at the central core are in general better captured by the $15 \mu \mathrm{m}$ and $10 \mu \mathrm{m}$ grids. Beyond $6 \mathrm{~mm}$ downstream, all the grids tend to over predict the values.

The projected density along the transverse direction comparing the simulations on different grid resolutions and x-ray radiography data is shown at $0.1 \mathrm{~mm}$ and $2 \mathrm{~mm}$ downstream of the nozzle exit in Figure 12(a) and Figure 12(b), respectively. Experimental profiles are not symmetric. Kastengren et al. (2014) have reported that the spray shape may be elliptical at nozzle exit. Figure 12(a) shows that the finer resolutions of $10 \mu \mathrm{m}$ and $15 \mu \mathrm{m}$ can capture the fuel distribution next to the nozzle exit very well. The $30 \mu \mathrm{m}$ grid also performs fairly well. Predictions with the $60 \mu \mathrm{m}$ minimum cell size are highly asymmetric due to insufficient resolution. The peak projected density is captured well by all the resolutions except $60 \mu \mathrm{m}$. At the further downstream locations of $2 \mathrm{~mm}$, simulations with all the resolutions tend to over-predict the radial dispersion. Overall the $10 \mu \mathrm{m}$ and $15 \mu \mathrm{m}$ minimum grid sizes provide a good match with the experimental data. Note that the $30 \mu \mathrm{m}$ grid can fairly well capture the trend.

The mass distribution data can be used to describe the trends in the axial spray velocity under steady-state conditions. It is described by Kastengren et al. (2009a) that the integral of the projected density across the transverse position at a particular axial location results in a quantity called transverse integrated mass (TIM). Based on a control volume analysis, the TIM is inversely proportional to the mass-averaged axial spray velocity at a given axial location. The TIM at any location is normalized with the TIM at the nozzle exit to obtain the relative velocity. This is used to 


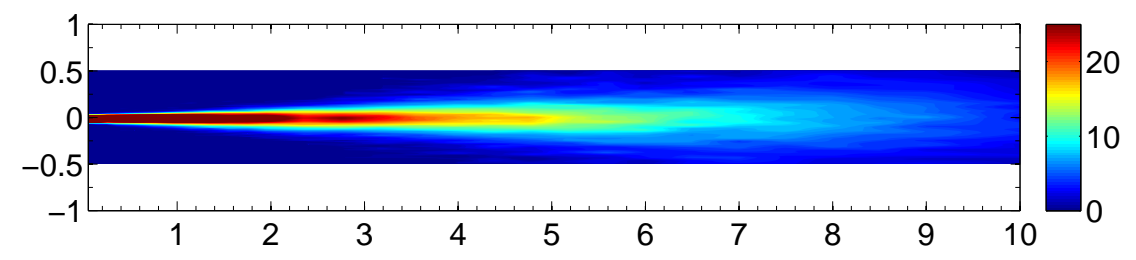

(a) X-ray measurement

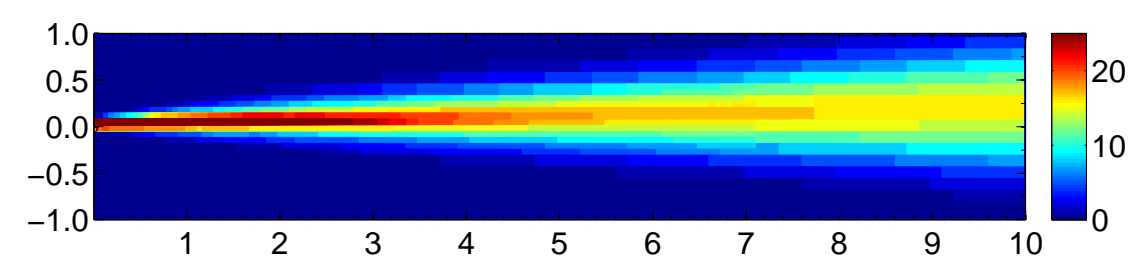

(b) $60 \mu \mathrm{m}$ grid

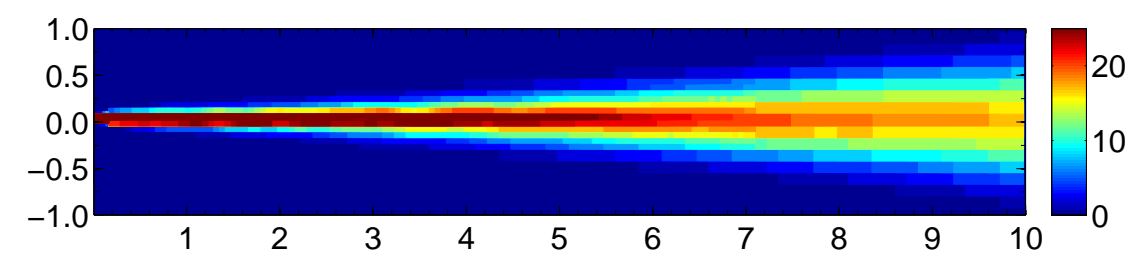

(c) $30 \mu \mathrm{m}$ grid

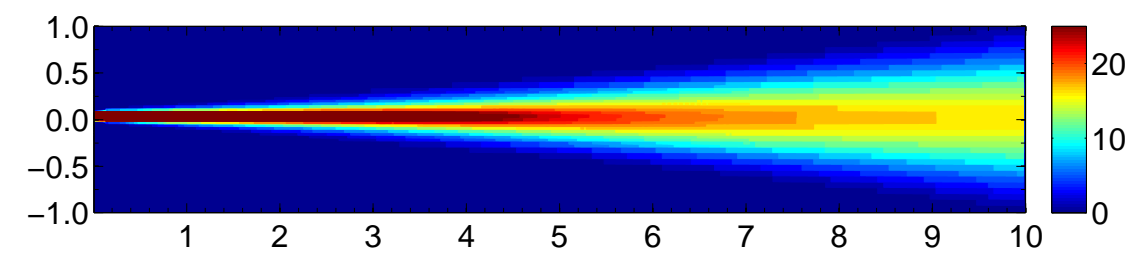

(d) $15 \mu \mathrm{m}$ grid

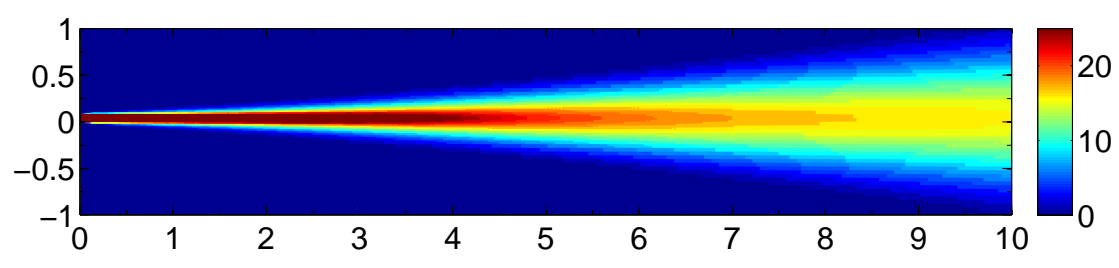

(e) $10 \mu \mathrm{m}$ grid

Figure 10: Projected mass density distributions $\left(\mu \mathrm{g} / \mathrm{mm}^{2}\right)$ at $510 \mu$ s ASOI from x-ray data and the baseline simulations with different grid sizes. Note that the X-ray data herein is ensemble-averaged over multiple shots. 


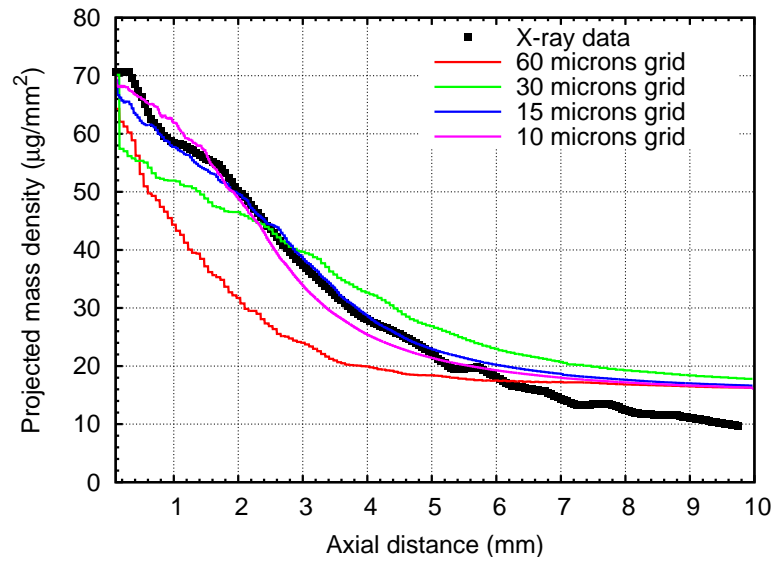

Figure 11: Comparison of projected density along the spray axis for simulations presented in Figure 10 against experimental data.

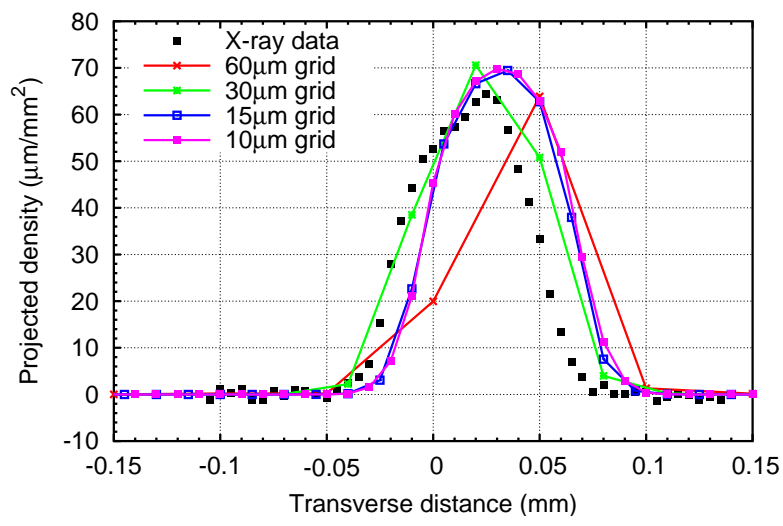

(a) $0.1 \mathrm{~mm}$

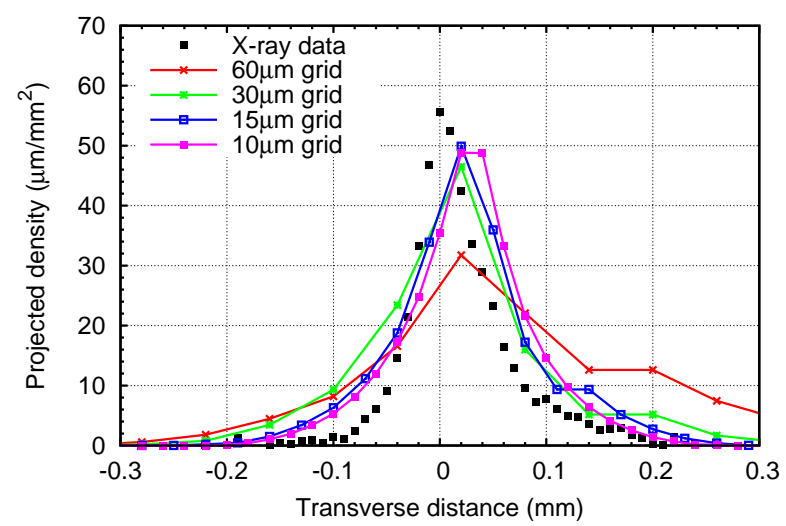

(b) $2.0 \mathrm{~mm}$

Figure 12: Comparison of projected density vs. transverse position at $510 \mu \mathrm{s}$ ASOI at axial locations of 0.1 and $2.0 \mathrm{~mm}$ downstream of the nozzle exit between simulations and experiments. 


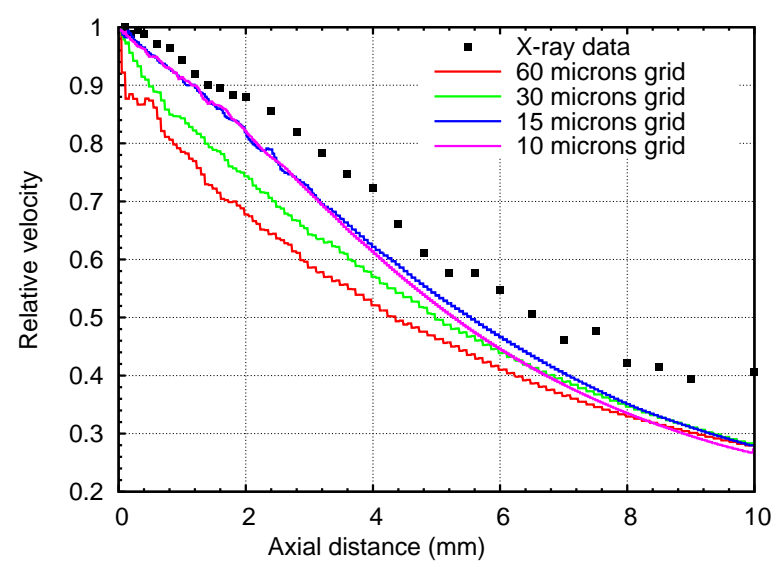

Figure 13: Comparison of mass-averaged spray velocity along the axis between simulations with different resolutions and x-ray radiography data at $0.51 \mathrm{~ms}$ ASOI.

compare the axial spray velocity decay with downstream distance between the simulations and x-ray data. Figure 13 shows the trends in the axial velocity decay predicted by simulations using the four grid sizes compared with measurement. All the simulations show steady velocity decay with downstream distance similar to the measurements. With the finer grid resolutions $(10 \mu \mathrm{m}$ and $15 \mu \mathrm{m})$, the trends are better captured. The over-predicted radial diffusion by the coarse meshes $(30 \mu \mathrm{m}$ and $60 \mu \mathrm{m})$ attributes to the lower relative velocity near the nozzle (Figure 13).

\subsection{Effect of turbulence model constants}

Following the mesh resolution study, the influence of $C_{\epsilon 1}$ on near nozzle fuel distribution is investigated. Figure 14 plots the simulated projected mass density distribution on $15 \mu \mathrm{m}$ mesh size using the standard turbulence model constant value $\left(C_{\epsilon 1}=1.44\right)$ for $S c_{t}=0.71$ (i.e., the baseline value). The radial spray dispersion is again marginally better predicted at the finest resolution of $15 \mu \mathrm{m}$. It can be observed that the standard turbulence constant (1.44) predicted significantly wider spray dispersion compared to the modified constant for round-jet (1.60) shown in Figure 10.

The projected density along the spray axis is also plotted for different $C_{\epsilon 1}$ values of 1.60 and 1.44 for the $15 \mu \mathrm{m}$ minimum cell size and compared against experimental data in Figure 15. It can be seen that the projected density along the spray axis is lower for the standard turbulence model constant (1.44) than the round-jet correction one (1.60), since a more radially dispersed liquid spray is predicted by the standard value of 1.44.

The projected mass density versus transverse position profiles with two different turbulence model constant $\left(\mathrm{C}_{\epsilon 1}\right)$ values of 1.60 and 1.44 on a $15 \mu \mathrm{m}$ mesh are given in Figure 16 at $0.1 \mathrm{~mm}, 2 \mathrm{~mm}$, and 4 mm downstream of the nozzle exit. At $0.1 \mathrm{~mm}$ the difference in results between these two model constants are negligible. At $2 \mathrm{~mm}$ and $4 \mathrm{~mm}$ downstream locations, the standard model constant (1.44) predicts a wider spray distribution than the round-jet correction which is also consistent with the contour plots in Figures 14.

Figure 17 shows the trends in the mass-weighted axial velocity decay predicted by two different turbulence model constant values. It can be observed that the velocity decays faster with the standard $C_{\epsilon 1}=1.44$ compared to the value 


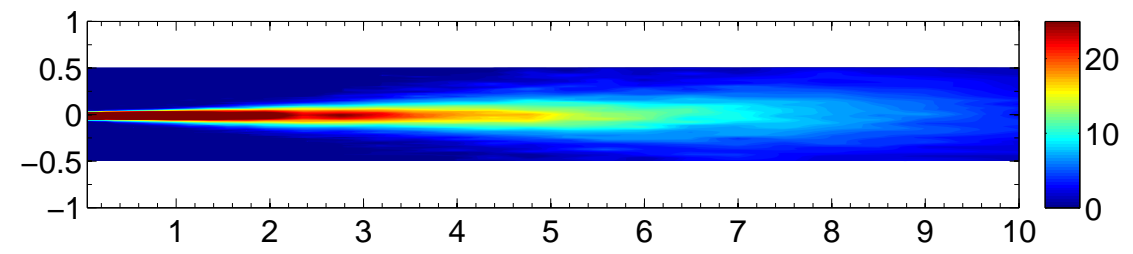

(a) X-ray measurement

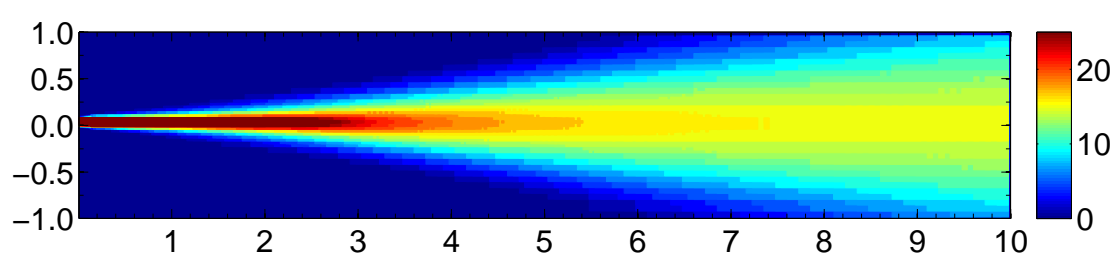

(b) $15 \mu \mathrm{m}$ grid

Figure 14: Projected mass density distributions $\left(\mu \mathrm{g} / \mathrm{mm}^{2}\right)$ at $510 \mu$ s ASOI from x-ray data and simulations $\left(C_{\epsilon 1}=1.44, S c_{t}=0.71\right)$ with $15 \mu \mathrm{m}$ minimum cell size.

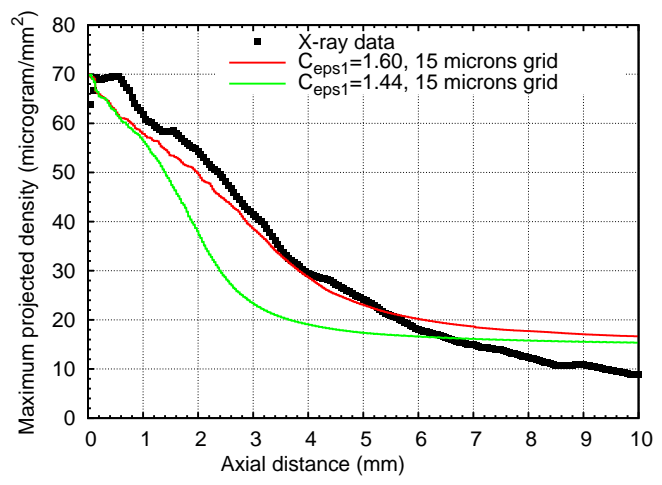

Figure 15: Comparison of projected mass density along the spray axis with different turbulence model constants and x-ray radiography data. 


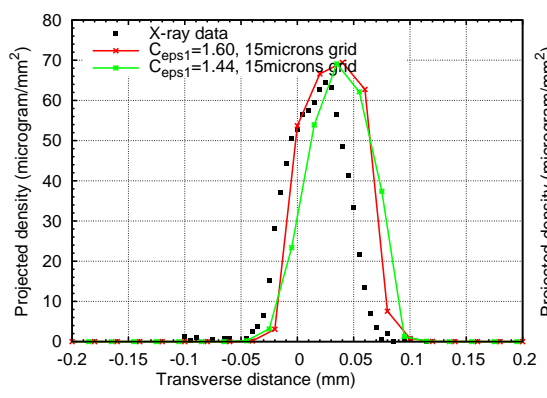

(a) $0.1 \mathrm{~mm}$ downstream

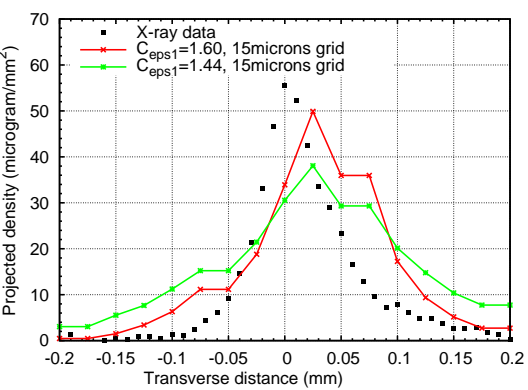

(b) $2 \mathrm{~mm}$ downstream

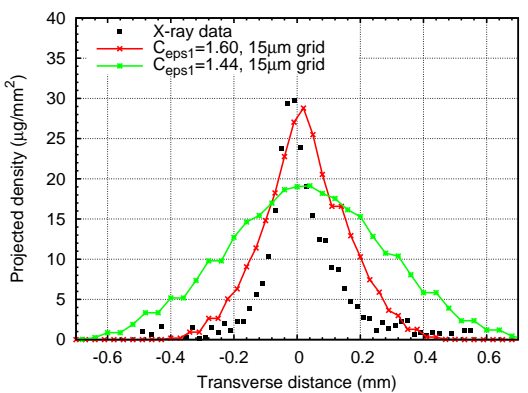

(c) $4 \mathrm{~mm}$ downstream

Figure 16: Comparison of projected mass density vs. transverse position at axial locations of $0.1 \mathrm{~mm}, 2 \mathrm{~mm}$, and $4 \mathrm{~mm}$ downstream of the nozzle exit with two different turbulence model constant values.

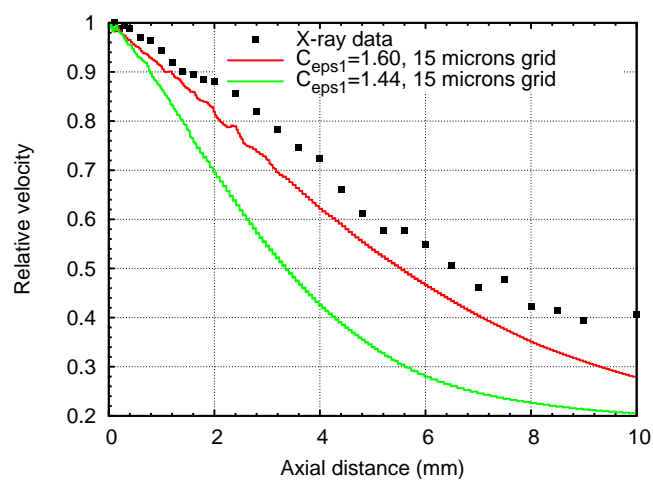

Figure 17: Comparison of mass-averaged spray velocity along the axis with two different turbulence model constants compared against the experimental data.

of $C_{\epsilon 1}=1.6$. Due to the fast axial velocity decay, the projected density contours are also broader with 1.44 (as shown in Figures 10 and 14).

\subsection{Effect of Schmidt number}

Schmidt number is also a parameter in the turbulent-mixing model term in Eqn. 3. Two Schmidt number values 0.71 and 0.9 were used to study the effect on near nozzle fuel distribution. To further quantify the effect of Schmidt number on the spray radial dispersion, Figure 18 plots the projected density distribution along the transverse position for the two axial locations of $0.1 \mathrm{~mm}$ and $2 \mathrm{~mm}$. Consistently, the transverse projected density distribution plots also show a minimal influence of Schmidt number on the near nozzle fuel distribution.

\subsection{Effect of needle off-axis motion}

The eccentric motions (wobble) of the injector needle and oscillations in the fuel density as it emerges from the nozzle were examined by Powell et al. (2011) using x-ray techniques. The influence of needle wobble on the nozzle exit and downstream spray can be studied using this coupled Eulerian spray model. In a previous study by the authors 


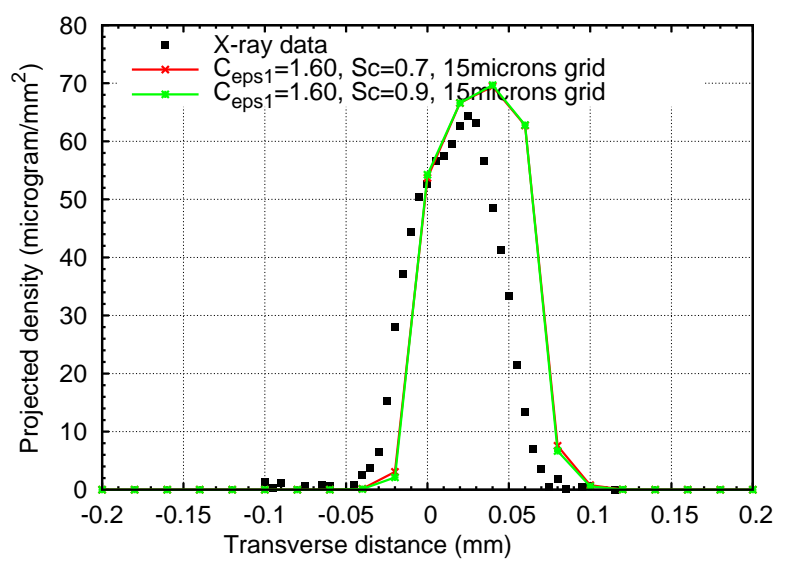

(a) $0.1 \mathrm{~mm}$ downstream

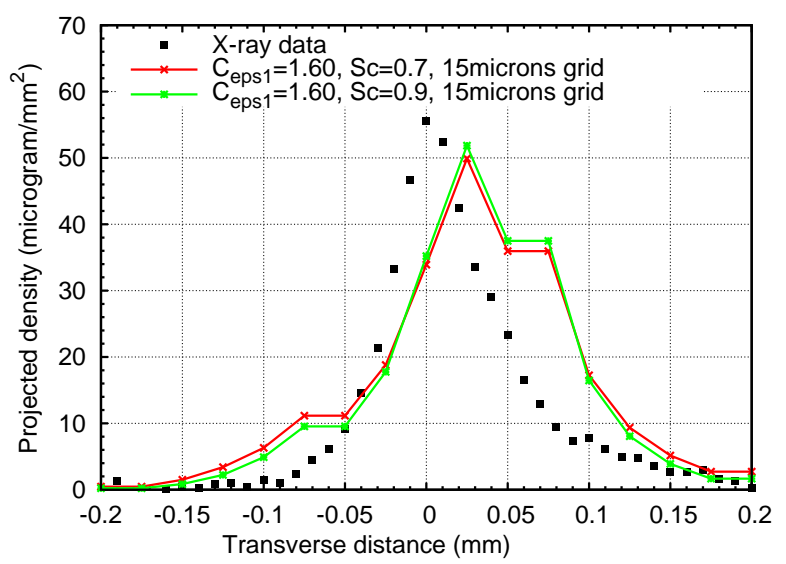

(b) $2 \mathrm{~mm}$ downstream

Figure 18: Comparison of projected density vs. transverse position between experiments and simulations at axial positions of $0.1 \mathrm{~mm}$, and $2 \mathrm{~mm}$, with $\mathrm{Sc}=0.71$ and $\mathrm{Sc}=0.90$ at $510 \mu$ s ASOI.

the needle off-axial motion did not seem to influence the in-nozzle flow development for the single-hole Spray A injector (Xue et al., 2013a). Consistent with this previous study, the needle wobble does not seem to significantly influence the near nozzle fuel distribution from the coupled simulations. Hence, the results comparing the influence of wobble and without wobble are not shown here.

\subsection{Coupled Eulerian spray model vs. Lagrangian-Eulerian spray approach}

The Eulerian model has been proposed for resolving the near nozzle dense spray region. The previous sections have discussed in detail the sensitivities of the Eulerian model to the choice of grid size and model constants. In the past the authors have also performed extensive Lagrangian spray simulations using the 'blob' injection model (Senecal et al., 2013a,b; Xue et al., 2013b; Senecal et al., 2014). The Lagrangian-Eulerian spray simulations were initialized with the recommended ROI in Figure 9. The minimum grid sizes are chosen such that they are similar between the Lagrangian $(62.5 \mu \mathrm{m})$ and Eulerian $(60 \mu \mathrm{m})$ simulations. The projected mass density distributions from both simulations are plotted with the x-ray data in Figure 19. Note that the same plotting resolution is used for Lagrangian and Eulerian models to obtain the mass density. The turbulent-mixing based Eulerian model better describes the near nozzle fuel distribution compared to the discrete-droplet-based assumption used in the Lagrangian-Eulerian approach. The work by Siebers $(1998,1999)$ indicates that turbulent spray mixing and gas entrainment perhaps play a more important role than local interphase transport processes that droplet dynamics emphasizes on in direct-injection diesel sprays. Hence, the turbulent-mixing based Eulerian model is perhaps more accurate for representing near nozzle spray jet physics.

The projected mass density distributions along the spray axis are plotted in Figure 20 from x-ray data and simulations. It is observed that the Eulerian approach prediction agrees better with measurement than the Lagrangian 


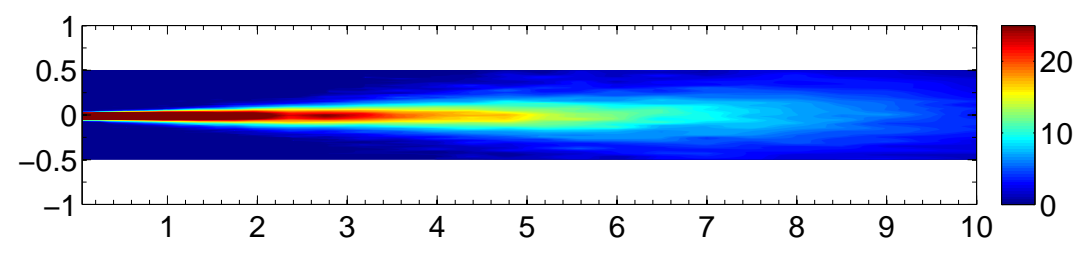

(a) X-ray measurement

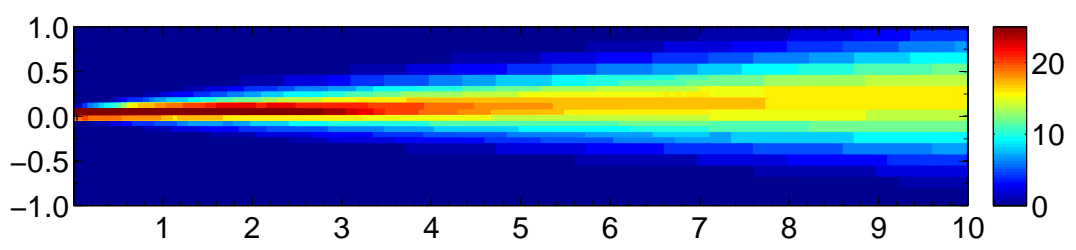

(b) Eulerian model on $62.5 \mu \mathrm{m}$ grid

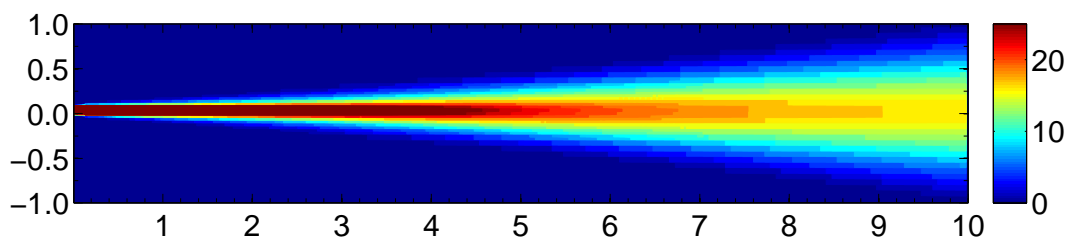

(c) Eulerian model on $15 \mu \mathrm{m}$ grid

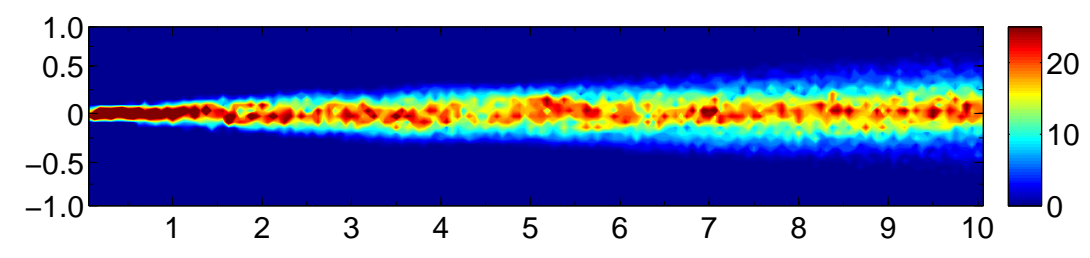

(d) Lagrangian model

Figure 19: Comparison of projected mass density distributions $\left(\mu \mathrm{g} / \mathrm{mm}^{2}\right)$ between experimental data, coupled Eulerian simulation, and LagrangianEulerian spray simulation at $510 \mu$ s ASOI. 


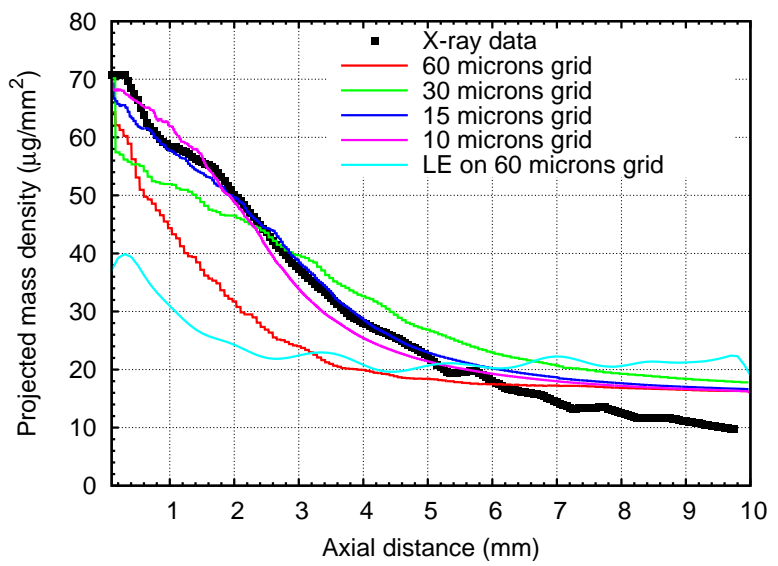

Figure 20: Comparison of projected mass density along the spray axis between LE with $62.5 \mu \mathrm{m}$ grid and EE with different grids against x-ray radiography data.

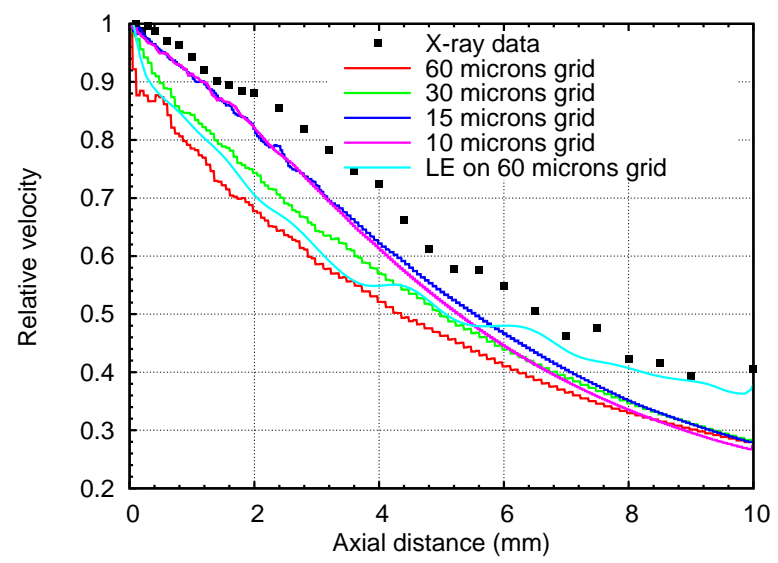

Figure 21: Comparison of mass-averaged spray velocity along the axis between LE with $62.5 \mu \mathrm{m}$ grid and EE with different grids against the experimental data.

approach on the same mesh resolution of $60 \mu \mathrm{m}$, particularly in the first $6 \mathrm{~mm}$ downstream from nozzle exit. The peak projected density for the LE model is rather flat, which is consistent with long regions of high mean density shown in the contour plot. Figure 21 shows the mass-averaged relative axial velocity along the spray axis from x-ray measurement and simulations from both Lagrangian and Eulerian approaches. Both models predict similar velocity decay along the spray axis in the near-nozzle region with a mesh resolution of $60 \mu \mathrm{m}$. However, the Eulerian model agrees better with a grid-converged $15 \mu \mathrm{m}$ mesh in near nozzle region. It is also observed that the Lagrangian approach agrees better beyond $6 \mathrm{~mm}$ than the Eulerian approach in Figure 21 although both models predict similar axial projected mass density in Figure 20.

Further comparisons are made for the transverse projected mass density distributions at different downstream locations in Figure 22. The Lagrangian model tends to under-predict the peak mass density along the spray axis in 


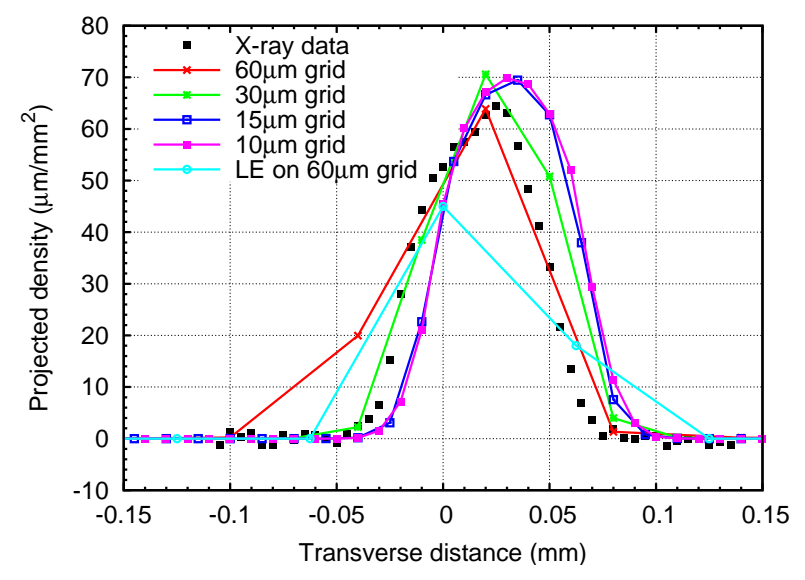

(a) $0.1 \mathrm{~mm}$ downstream

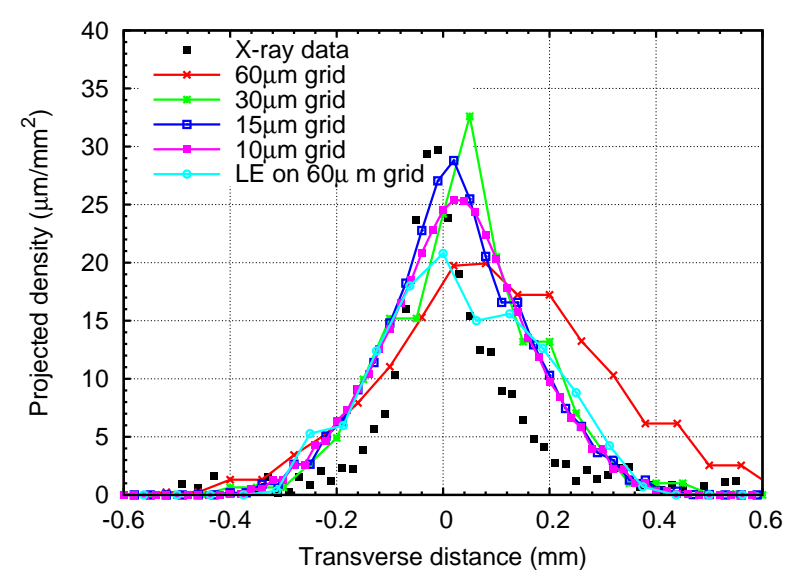

(c) $4 \mathrm{~mm}$ downstream

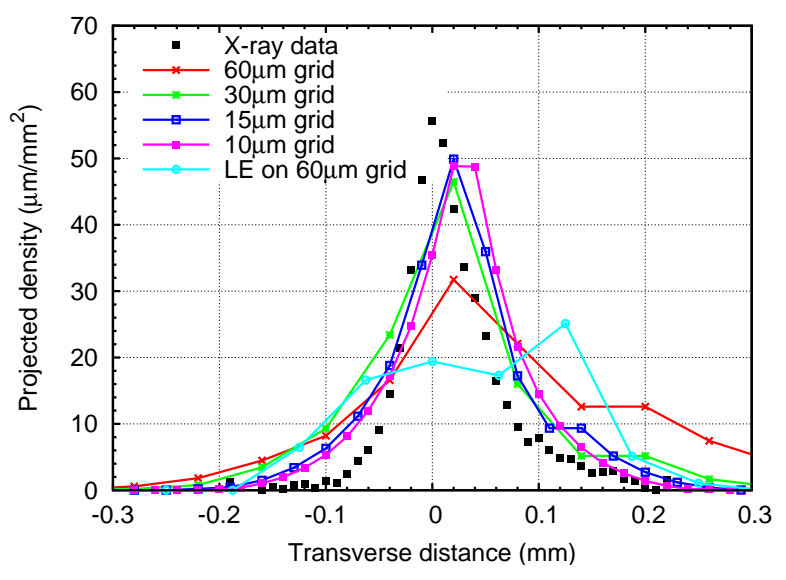

(b) $2 \mathrm{~mm}$ downstream

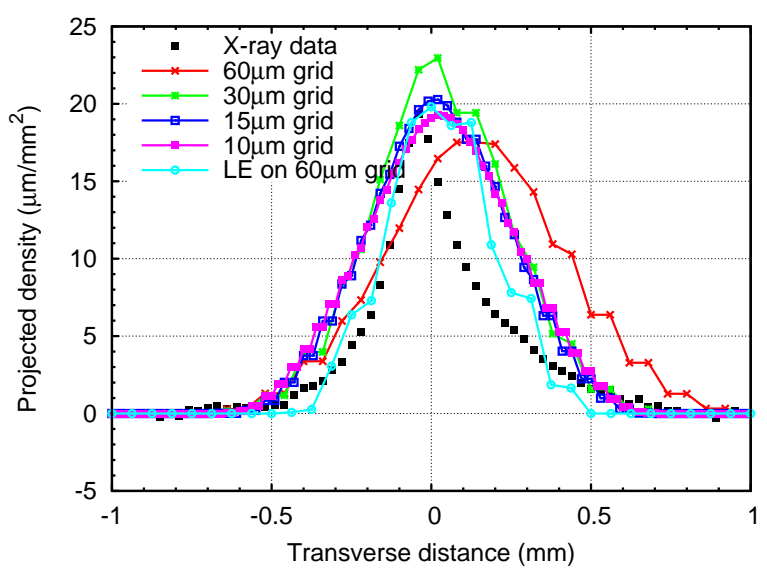

(d) $6 \mathrm{~mm}$ downstream

Figure 22: Comparison of projected mass density vs. transverse position at axial locations of $0.1 \mathrm{~mm}, 2 \mathrm{~mm}$, and $4 \mathrm{~mm}$ downstream of the nozzle exit between LE with $62.5 \mu \mathrm{m}$ grid and EE with different grids against the experimental data. 
the near-nozzle region (Figures 22(a), 22(b), and 22(c)) compared to the Eulerian model on $60 \mu \mathrm{m}$ mesh. At further downstream location (Figure 22(d)), both models can predict similar projected mass density peak value and profile. The Lagrangian approach also shows better agreement with $\mathrm{x}$-ray data at $6 \mathrm{~mm}$ downstream location than Eulerian approach in terms of radial dispersion. The decreased dispersion beyond $6 \mathrm{~mm}$ downstream using the Lagrangian approach can also be observed clearly in the 2-D contour plot in Figure 19.

\section{Summary and conclusions}

This paper implemented a turbulent-mixing based Eulerian model to better predict the near-nozzle dense spray, and provided a framework to fully couple nozzle flow and downstream sprays. The model was implemented using the VOF method in CONVERGE code. Fully coupled nozzle flow and downstream spray simulations were performed with the single-hole Spray A injector under non-evaporating conditions. X-ray radiography measurements from Argonne National Laboratory were used for validation purposes since the x-ray data can provide quantitative near nozzle fuel density distributions. The simulations were specifically validated against the near nozzle data rather than the typically simulated global parameters such as liquid penetration, cone angle, and SMD etc.

The Eulerian model predicted the ROI characteristics very well and could also capture the near nozzle fuel distribution in the coupled simulations. The simulation results improved significantly with finer resolution and grid convergence was demonstrated. The turbulence model constant was seen to have a profound influence on the Eulerian model results. The round jet correction suggested in the literature improved the fuel distribution significantly in terms of the radial dispersion. Schmidt number was seen to have a rather small influence on the simulation results at least in the near nozzle region. With the fully-coupled approach, parametric studies were also performed to study the influence of needle wobble on spray development. For the single-hole Spray A injector, needle wobble had only a marginal influence on nozzle flow and spray results. There was no cavitation occurring from the numerical results, which was also true from experimental observation for this injector with convergent nozzle.

Finally the Eulerian model predictions were also compared against the Lagrangian model predictions. Both qualitatively and quantitatively the Eulerian model results were in better agreement with the experimental data in the first $6 \mathrm{~mm}$ of the near-nozzle region which was demonstrated by the projected mass density and relative velocity. This study demonstrated that a fully-coupled nozzle flow and spray modeling approach within the Eulerian framework can be developed to be more predictive in nature, especially in the near nozzle region. Future studies will focus on further improving the simulation results by implementing higher fidelity turbulence models. The coupled approach can directly incorporate the in-nozzle features such as turbulence, cavitation, needle motion, and geometrical effects into spray simulations. 


\section{Acknowledgments}

This research was funded by DOEs Office of Vehicle Technologies, Office of Energy Efficiency and Renewable Energy. The authors wish to thank Gurpreet Singh and Leo Breton, team leader at DOE, for his support. This research was performed at the 7-BM and 32-ID beam lines of the APS at Argonne National Laboratory. Use of the APS is supported by the U.S. Department of Energy (DOE) under Contract No. DE-AC02-06CH11357.

We gratefully acknowledge the computing resources provided on "Fusion", a 320-node computing cluster operated by the Laboratory Computing Resource Center at Argonne National Laboratory.

\section{References}

Amsden, A. A., O'Rourke, P. J., Butler, T. D., 1989. KIVA-II: A computer program for chemically reactive flows with sprays. LA-11560-MS (LA11560-MS).

Arcoumains, C., Gavaises, M., 1998. Linking nozzle flow with spray characteristics in a diesel fuel injection system. Atomization and Sprays 8 , 307-347.

Are, S., Hou, S., Schmidt, D., 2005. Second-order spatial accuracy in lagrangian-eulerian spray calculations. Numerical Heat Transfer, PartB: Fundamentals 48 (1), 25-44.

Battistoni, M., Grimaldi, C., 2012. Numerical analysis of injector flow and spray characteristics from diesel injectors using fossil and biodiesel fuels. Applied Energy 97, 656-666.

Battistoni, M., Som, S., Longman, D. E., 2014. Comparison of mixture and multi-fluid models for in-nozzle cavitation prediction. Journal of Engineering for Gas Turbines and Power 136 (6), 061506-12.

Bekdemir, C., Somers, L., Goey, L. D., Tillou, J., Angelberger, C., 2013. Predicting diesel combustion characteristics with large-eddy simulations including tabulated chemical kinetics. Proceedings of the Combustion Institute 34, 3067-3074.

Bergwerk, W., 1959. Flow pattern in diesel nozzle spray holes. Proceedings of the Institution of Mechanical Engineers 173, 655-660.

Bilicki, Z., Kestin, J., 1990. Physical aspects of the relaxation model in two-phase flow. Proceedings of the Royal Society A 428, 379-397.

Chang, S., Haworth, D., 1997. Adaptive grid refinenment using cell-level and global imbalances. International Journal of Numerical Methods in Fluids 24, 375-392.

Chesnel, J., Reveillon, J., Menard, T., Demoulin, F. X., 2012. Large eddy simulation of liquid jet atomization. Atomization and Sprays 21 (9), 711-736.

CMT, 2013. CMT. http://www.cmt.upv.es/ECN03.aspx.

Demoulin, F. X., Beau, P. A., Blokkeel, G., Mura, A., Borghi, R., 2007. A new model for turbulent flows with large density fluctuations: application to liquid atomization. Atomization and Sprays 17, 315-345.

Dukowicz, J., 1980. A particle fluid numerical model for liquid sprays. Journal of Computational Physics 2, 111-566.

Duret, B., Reveillon, J., Menard, T., Demoulin, F. X., 2013. Improving primary atomization modeling through dns of two-phase flows. International Journal of Multiphase Flow 55, 130-137.

ECN, 2010. Engine combustion network. www.sandia.gov/ecn.

Garcia-Oliver, J. M., Pastor, J. M., Pandal, A., Trask, N., Baldwin, E., Schmidt, D. P., 2013. Diesel spray cfd simulations based on the sigma-y eulerian atomizaton model. Atomization and Sprays 23 (1), 71-95.

Habchi, C., Dumont, N., Simonin, O., 2008. Multidimensional simulation of cavitating flows in diesel injectors by a homogeneous mixture modeling approach. Atomization and Sprays 18, 129-162.

Hou, S., Schmidt, D. P., 2006. Adaptive collision meshing and satellite droplet formation in spray simulations. International Journal of Multiphase Flow 32 (8), 935-956. 
Kastengren, A., Powell, C. F., 2007. Spray density measurements using x-ray radiography. Proceedings of the Institution of Mechanical Engineers, Part D: Journal of Automobile Engineering 221, 653-662.

Kastengren, A., Powell, C. F., Wang, Y.-J., Im, K.-S., Wang, J., 2009a. X-ray radiography measurements of diesel spray structure at engine-like ambient density. Atomization and Sprays 19 (11), 1031-1044.

Kastengren, A. L., Powell, C. F., Liu, Z., Wang, J., 2009b. Time resolved, three dimenstional mass distribution of diesel sprays measured with X-ray radiography. SAE Technical Paper 2009-01-0840.

Kastengren, A. L., Tilocco, F. Z., Duke, D., Powell, C. F., Zhang, X., Moon, S., 2014. Time-resolved x-ray radiogrpahy of sprays from engine combustion network spray a diesel injectors. Atomization and Sprays 24 (3), 251-272.

Kong, S., Sun, Y., Reitz, R., 2007. Modeling diesel spray flame lift-off, sooting tendency, and nox emissions using detailed chemistry with phenomenological soot model. Journal of Engineering for Gas Turbines and Power 129 (1), 245-251.

Lebas, R., Blokkeel, G., Beau, P. A., Demoulin, F. X., 2005. Coupling vaporization model with the eulerian- lagrangian spray atomization (ELSA) model in diesel engine conditions. SAE Technical Paper 2005-01-0213.

Lebas, R., Menard, T., Beau, P. A., Berlemont, A., Demoulin, F. X., 2009. Numerical simulation of primary break-up and atomization: DNS and modelling study. International Journal of Multiphase Flow 35, 247-260.

Leick, P., Grzeszik, R., Armdt, S., Wissel, S., September 2011. Suppression of multiple scattering using structured light sheets - A first asseeement for diesel and gasoline spray visualization. 24th ILASS-Europe Conference on Liquid Atomization and Spray Systems.

Linne, M., Paciaroni, M., Hall, T., Parker, T., 2006. Ballistic imaging of the near field in a diesel spray. Experiments in Fluids 40, 836-846.

Liu, A., Reitz, R. D., 1993. Modeling the effects of drop drag and breakup on fuel sprays. SAE Technical Paper 930072.

Lucchini, T., D’Errico, G., Ettore, D., Ferrari, G., 2009. Numerical investigation of nonreacting and reacting diesel sprays in constant volume vessels. SAE Technical Paper 2009-01-1971.

Martinez, L., Benkenida, A., Cuenot, B., 2010. A model for the injection boundary conditions in the context of 3d simulation of diesel spray: methodology and validation. Fuel 89, 219-228.

Naber, J., Siebers, D., 1996. Effects of gas density and vaporization on penetration and dispersion of diesel sprays. SAE Technical Paper 960034.

Ning, W., Reitz, R. D., Diwakar, R., Lippert, A. M., 2009. An Eulerian-Lagrangian spray and atomization model with improved turbulence modeling. Atomization and Sprays 19 (8), 727-739.

Patterson, M. A., Reitz, R. D., 1998. Modeling the effects of fuel spray characteristics on diesel engine combustion and emissions. SAE Technical Paper 980131.

Payri, R., Garcia, J., Salvador, F., Gimeno, J., 2005. Using spray momentum flux measurements to understand the influence of diesel nozzle geometry on spray characteristics. Fuel 84, 551-561.

Pickett, L., Genzale, C., Bruneaux, G., Malbec, L., Hermant, L., Christiansen, C., Schramm, J., 2010. Comparison of diesel spray combustion in different high-temperature, high-pressure facilities. SAE Technical Paper 2010-01-2106.

Pickett, L., Siebers, D., 2004. Soot in diesel fuel jets: effects of ambient temperature, ambient density, and injection pressure. Combustion and Flame 138, 114-135.

Pickett, L. M., Manin, J., Kastengren, A. L., Powell, C. F., 2014. Comparison of near-field structure and growth of a diesel spray using light-based optical microscopy and x-ray radiography. SAE Technical Paper 2014-01-1412.

Pope, S., 1978. An explanation of the turbulent round-jet/plane-jet anomaly. AIAA Journal 16, 279-281.

Powell, C. F., Ciatti, S., Cheong, S.-K., Liu, J., Wang, J., 2004. X-ray absorption measurement of diesel sprays and the effect of nozzle geometry. SAE Technical Paper 2004-01-2011.

Powell, C. F., Kastengren, A. L., Liu, Z., Fezzaa, K., 2011. The effects of diesel injector needle motion on spray structure. Journal of Engineering for Gas Turbines and Power 133, 0128021-9.

Quan, S., Dai, M., Pomraning, E., Senecal, P., Richards, K., Som, S., Skeen, S., Manin, J., Pickett, L., 2014. Numerical simulations of supersonic diesel spray injection and the induced shock waves. SAE International Journal of Engines 7 (2), 1-8.

Reitz, R., Rutland, C. J., 1995. Development and testing of diesel engine cfd models. Progress in Energy and Combustion Science 21, $173-196$. 
Reitz, R. D., 1987. Modeling atomization processes in high-pressure vaporizing sprays. Atomization and Sprays Technology 3 (4), $309-337$.

Reitz, R. D., Diwakar, R., 1987. Structure of high-pressure fuel sprays. SAE Technical Paper 870598.

Salvador, F. J., Gimeno, J., Pastor, J. M., Marti-Aldaravi, P., 2014. Effect of turbulence model and inlet boundary condition on the diesel spray behavior simulated by an eulerian spray atomization (esa) model. International Journal of Multiphase Flow 65, 108-116.

Schmidt, D., 2006. Theoretical analysis for achieving high-order spatial accuracy in lagrangian/eulerian source terms. International Journal of Numerical Methods in Fluids 52, 843-865.

Schmidt, D., Gopalakrishnan, S., Jasak, H., 2010. Multi-dimensional simulation of thermal non-equilibrium channel flow. International Journal of Multiphase Flow 36, 284-292.

Schmidt, D., Rutland, C. J., 2000. A new droplet collision algorithm. Journal of Computational Physics 164, 62-80.

Schmidt, D., Rutland, C. J., 2004. Reducing grid dependency in droplet collision modeling. ASME Journal of Engineeing for Gas Turbines and Power 126, 227-233.

Schmidt, D., Rutland, C. J., Corradini, M. L., 1999. A fully compressible, two-dimensional model of small, high-speed, cavitating nozzles. Atomization and Sprays 9, 255-276.

Schmidt, D., Senecal, P., 2002. Improving the numerical accuracy of spray simulations. SAE Technical Paper 2002-01-1113.

Senecal, P., Pomraning, E., Richards, K., 2003. Multidimensional modeling of direc-injection diesel spray liquid length and flame lift-off length using cfd and parallel detailed chemistry. SAE Technical Paper 2003-01-1043.

Senecal, P., Pomraning, E., Richards, K., Som, S., 2013a. Grid convergent spray models for internal combustion engines CFD simulations. Journal of Energy Resources Technology 136 (1), 12204.

Senecal, P., Pomraning, E., Richards, K., Som, S., 2013b. An investigation of grid convergence for spray simulation using an LES turbulence model. SAE Technical Paper 2013-01-1083.

Senecal, P., Pomraning, E., Xue, Q., Som, S., Banerjee, S., Hu, B., Liu, K., Deur, J., 2014. Large eddy simulation of vaporizing sprays considering multi-injection averaging and grid-convergent mesh resolution. Journal of Engineering for Gas Turbines and Power 136 (11), 111504.

Senecal, P., Richards, K., Pomraning, E., Yang, T., Dai, M., McDavid, R. M., Patterson, M. A., Hou, S., Sethaji, T., 2007. A new parallel cut-cell cartesian cfd code for rapid grid generation applied to in-cylinder diesel engine simulations. SAE Technical Paper 2007-01-0159.

Sick, V., Stojkovic, B., 2001. Attenuation effects on imaging diagnostics of hollow-cone sprays. Applied Optics 40 (15), 2435-42.

Siebers, D., 1998. Liquid phase fuel penetration in diesel sprays. SAE Technical Paper 980809.

Siebers, D. L., 1999. Scaling liquid-phase fuel penetration in diesel sprays based on mixing-limited vaporization. SAE Technical Paper 1999-010528.

Som, S., Aggarwal, S., 2010. Effects of primary breakup modeling on spray and combustion characteristics of compression ignition engines. Combustion and Flame 157, 1179-1193.

Som, S., Ramirez, A., Aggarwal, S. K., Kastengren, A., EI-Hannouny, E., Longman, D. E., Powell, C. F., Senecal, P., 2009. Development and validation of a primary breakup model for diesel engine applications. SAE Technical Paper 2009-01-0838.

Som, S., Ramirez, A. I., Longman, D. E., Aggarwal, S. K., 2011. Effects of nozzle orifice geometry on spray, combustion, and emission characteristics under diesel engine conditions. Fuel 90, 1267-1276.

Soteriou, C., Andrews, R., Torres, N., Smith, M., Kunkulagunta, R., 2001. Through the diesel nozzle hole - a journal of discovery. In: 14th Annual ILASS Americas Conference. Dearborn MI, USA.

Soteriou, C., Lambert, M., Zuelch, S., Passerel, D., 2006. The flow characteristics of high efficiency diesel nozzles with enhanced geometry holes. In: Proceedings of THIESEL International Conference on Thermo and Fluid Dynamic Processes in Diesel Engines. Valencia, Spain.

Torres, D. J., Trujillo, M. F., 2006. Kiva-4: An unstructured ale code for compressible gas flow with sprays. Journal of Computational Physics 219 , 943-975.

Trask, N., Schmidt, D. P., Lightfoot, M., Danczyk, S., 2012. Compressible modeling of the internal flow in a gas-centered swirl-coaxial fuel injector. Journal of Propulsion and Power 28 (4), 685-693.

U.S. DOE, March 2011. A workshop to identify research needs and impacts in predictive simulation for internal combustion engines (PreSICE). 
Workshop, U.S. Department of Energy.

Vallet, A., Burluka, A. A., Borghi, R., 2001. Development of a eulerian model for the "atomization" of a liquid jet. Atomization and Sprays 11, 619-642.

von Berg, E., Alajbegovic, A., Greif, D., Poredos, A., Tatschl, R., Winkelhofer, E., Ganippa, L., 2002. Primary break-up model for diesel jets based on locally resolved flow field in the injection hole. ILASS-Europe.

von Berg, E., Edelbauer, W., Alajbegovic, A., Tatschl, R., Volmajer, M., Kegl, B., Ganippa, L., 2005. Coupled simulations of nozzle flow, primary fuel jet breakup, and spray formation. Journal of Engineering for Gas Turbines and Power 127, 879-90.

Wang, Y., Lee, W., Reitz, R. D., 2011. Numerical simulation of diesel spray using an Eulerian-Lagrangian spray and atomization (ELSA) model coupled with nozzle flow. SAE Technical Paper 2011-01-0386.

Wang, Y., Qiu, L., Reitz, R. D., Diwakar, R., 2014. Simulating cavitating liquid jets using a compressible and equilibrium two-phase flow solver. International Journal of Multiphase Flow 63, 52-67.

Xue, Q., Kong, S., 2009. Development of adaptive mesh refinement scheme for engine spray simulations. Computer and Fluids 38, 939-949.

Xue, Q., Kong, S., Torres, D. J., Xu, Z., Yi, J., 2008. Disi spray modeling using local mesh refinement. SAE Technical Paper 2008-01-0967.

Xue, Q., Som, S., Battistoni, M., Longman, D. E., Zhao, H., Senecal, P., Pomraning, E., May 2013a. Three-dimensional simulations of the transient internal flow in a diesel injector: effects of needle movement. ILASS 2013, 25th Annual Conference on Liquid Atomization and Spray Systems.

Xue, Q., Som, S., Pomraning, E., Senecal, P., 2013b. Large eddy simulation of fuel-spray under non-reacting IC engine conditions. Atomization and Sprays $23(10), 925-55$.

Zhao, H., Quan, S., Dai, M., Pomraning, E., Senecal, P., Xue, Q., Battistoni, M., Som, S., 2014. Validation of a three-dimensional internal nozzle flow model including automatic mesh generation and caviation effects. Journal of Engineering for Gas Turbines and Power 136, $092603-1$. 